UNIVERSIDADE DE SÃO PAULO

ESCOLA DE ENFERMAGEM

JOESE APARECIDA CARVALHO

O MANEJO DA DOR EM CRIANÇAS HOSPITALIZADAS:

UM ESTUDO RETROSPECTIVO

SÃO PAULO

2019 
JOESE APARECIDA CARVALHO

\title{
O MANEJO DA DOR EM CRIANÇAS HOSPITALIZADAS: \\ UM ESTUDO RETROSPECTIVO
}

\author{
Versão corrigida da Dissertação apresentada ao \\ Programa de Pós-Graduação em Enfermagem da Escola \\ de Enfermagem da Universidade de São Paulo para \\ obtenção do título de Mestre em Ciências \\ Área de concentração: Cuidados em Saúde
}

Orientador: Profa. Dra. Lisabelle Mariano Rossato

\begin{abstract}
VERSÃO CORRIGIDA
A versão original encontra-se disponível na Biblioteca da Escola de Enfermagem da Universidade de São Paulo e na Biblioteca Digital de Teses e Dissertações da Universidade de São Paulo
\end{abstract}

\section{SÃO PAULO}


AUTORIZO A REPRODUÇÃO E DIVULGAÇÃO TOTAL OU PARCIAL DESTE TRABALHO, POR QUALQUER MEIO CONVENCIONAL OU ELETRÔNICO, PARA FINS DE ESTUDO E PESQUISA, DESDE QUE CITADA A FONTE.

Assinatura:

Data:

\section{Catalogação na Publicação (CIP) \\ Biblioteca "Wanda de Aguiar Horta" \\ Escola de Enfermagem da Universidade de São Paulo}

Carvalho, Joese Aparecida

O manejo da dor em crianças hospitalizadas: um estudo retorspectivo / Joese Aparecida Carvalho. São Paulo, 2019. $72 \mathrm{p}$.

Dissertação (Mestrado) - Escola de Enfermagem da Universidade de São Paulo.

Orientadora: Prof. ${ }^{\text {a }}$ Dr.. L Lisabelle Mariano Rossato

Área de concentração: Cuidados em Saúde

1. Dor. 2. Crianças. 3. Pacientes internados. 4. Enfermagem pediátrica. I. Título. 
Nome: Joese Aparecida Carvalho

Título: O manejo da dor em crianças hospitalizadas: Um estudo retrospectivo.

Dissertação apresentada ao Programa de Pós-Graduação em Enfermagem da Escola de Enfermagem da Universidade de São Paulo para obtenção do título de Mestre em Ciências

Aprovado em:

\section{Banca Examinadora}

Orientador: Prof. Dr.

Instituição:

Assinatura:

Prof. Dr. Instituição:

Julgamento: Assinatura:

Prof. Dr. Instituição:

Julgamento: Assinatura:

Prof. Dr. Instituição:

Julgamento: Assinatura: 
A Ele que tudo me deu...

A Ele que em tudo me conhece... A Deus dedico e agradeço cada momento vivido...

"Ó Senhor, nosso Deus, como é grande vosso nome por todo o universo!" (Sᄃ 8) 
Aos meus pais, pelos ensinamentos, pelos valores transmitidos e pelo apoio incondicional, os principais responsáveis por essa conquista.

Aos meus filhos que caminham ao meu lado diariamente.

Aminha irmã e minha família pelos momentos divertidos e por acreditarem em mim.

Aos meus amigos, aos quais pertenço e que me pertencem também, por todo ombro recebido, por todos os cafés, por todo amor que eu conheci nos momentos dificeis e que vivem alegremente no meu coração.

A minha orientadora Profa $\mathfrak{D r}^{a}$ Lisabelle Mariano Rossato pela confiança, pelo apoio e por sempre me lembrar do amor de Deus por nós. 
Carvalho JA. O manejo da dor em crianças hospitalizadas: um estudo retrospectivo [dissertação]. São Paulo: Escola de Enfermagem, Universidade de São Paulo; 2019.

\section{RESUMO}

Introdução: Independente do instrumento utilizado para a avaliação da dor da criança, o primordial é que este possibilite ao profissional a construção de um plano de intervenções que atenda individualmente cada criança. O conhecimento técnico da equipe é essencial para a realização de avaliações criteriosas de dor. É necessário identificar a maneira como é realizada a avaliação da dor e quais as ações adotadas para alívio da dor. Objetivo geral: Identificar como é realizado o manejo da dor em crianças internadas, mediante análise de registro em prontuários.

Método: Trata-se de um estudo retrospectivo, de abordagem quantitativa, realizado por meio de análise de registros em prontuários de crianças internadas em um Hospital Escola do Município de São Paulo. Para a coleta foi elaborado um instrumento para anotação dos registros, composto por dados demográficos, da internação e informações a respeito dos aspectos relacionados à dor durante o período de internação. Os dados foram armazenados em planilha Microsoft Office Exce® e analisados com o programa estatístico R3.5.3. As variáveis foram analisadas com estatística descritiva. Para a análise das associações entre as variáveis independentes e dependentes, foram aplicados os testes de Pearson's, teste Qui-quadrado, teste de Kruskal-Wallis rank sum, teste de Kruskal-Wallis Quiquadrado e Teste Exato de Fischer. O nível de significância estatística adotado foi de $5 \%$. O projeto de pesquisa recebeu aprovação das duas instituições. Resultados: Foram analisados 1728 prontuários, resultando em uma amostra de 1251 prontuários. Dessa amostra, 38,7\% ( $\mathrm{N}=481)$ apresentaram dor. Dentro da amostra de prontuários o registro de crianças internadas do sexo feminino foi de $42,6 \%$ ( $N=533$ ) e do sexo masculino foi de $57,3 \%$ ( $N=718)$. A média de idade das crianças internadas foi de 3,6 anos e a média do período de internação foi de cinco dias. A descrição da intensidade da dor foi considerada pelo instrumento de avaliação aplicado durante o período de internação. Além disso, foi considerado o registro de maior score dentro de todo o período de avaliação da criança durante a internação. Apresentaram dor intensa em algum período da internação, as crianças avaliadas com a escala FLACC, 41,5\%; numérica, 67,7\%; FACES, 73,5\% e NIPS, $37,2 \%$. A escala FLACC foi usada para avaliar $73,3 \%$ das crianças; a numérica em 
21,3\%; a FACES em 3,5\% e a NIPS em 5,6\%. Das crianças internadas no período investigado, 86\% ( $\mathrm{N}=1075)$ tinham em seu prontuário analgesia prescrita. A adoção de medidas não farmacológicas para alívio da dor foi de $0,48 \%(\mathrm{~N}=6)$. O diagnóstico "dor aguda" foi eleito para $30,1 \%(\mathrm{~N}=375)$. Estabelecendo a relação entre a presença de dor e a eleição do diagnóstico "dor aguda", observou-se que ele foi adotado para $53,85 \%(\mathrm{~N}=259)$ das crianças que apresentaram dor em algum momento da internação. O diagnóstico "dor aguda" não foi eleito para 46,1\% $(\mathrm{N}=222)$ das crianças que tiveram dor e foi eleito para $14,8 \%(\mathrm{~N}=113)$ das crianças internadas que não apresentaram dor em nenhum momento da internação. A partir da amostra total da pesquisa ( $\mathrm{N}=1251$ prontuários) obteve-se $15,5 \%(\mathrm{~N}=194)$ de registro de reavaliações. Conclusão: a frequência do dor nas crianças internadas foi de 38,7\%; as crianças avaliadas com escalas de autorrelato apresentaram maior intensidade de dor em algum momento da internação. A escala FLACC foi a mais usada para avaliação das crianças internadas. A adoção de medidas não farmacológicas para o alívio da dor é pouco frequente, assim como a reavaliação da dor não é realizada de maneira satisfatória.

PALAVRAS-CHAVE: Criança. Medição de dor. Enfermagem pediátrica. Dor. 
Carvalho JA. The pain management in hospitalized children: a retrospective study [dissertation]. São Paulo: Escola de Enfermagem, Universidade de São Paulo; 2019.

\section{ABSTRACT}

Introduction: Regardless of the instrument used to assess the pain of the child, the most important is that it allows the professional to construct a plan of interventions that meets each child individually. The technical knowledge of the team is essential for the careful evaluation of pain. It is necessary to identify the way pain assessment is performed and what actions are taken to relieve pain. General objective: To identify how the management of pain in hospitalized children is performed, through analysis of records in medical records. Method: This is a retrospective, quantitative approach, carried out by analyzing records in medical records of children hospitalized at a Hospital Escola do Município de São Paulo. For the collection, an instrument was used to record the records, composed of demographic data, hospitalization and information regarding aspects related to pain during the hospitalization period. The data were stored in a Microsoft Office Excel® worksheet and analyzed with statistical software R3.5.3. The variables were analyzed with descriptive statistics. Pearson's tests, Chi-square test, Kruskal-Wallis rank sum test, Kruskal-Wallis Chi-square test and Fischer's exact test were applied for the analysis of associations between independent and dependent variables. The level of statistical significance adopted was $5 \%$. The research project was approved by the two institutions. Results: 1728 medical records were analyzed, resulting in a sample of 1251 medical records. Of this sample, $38.7 \%(\mathrm{~N}=481)$ presented pain. Within the sample of medical records, $42.6 \%$ of hospitalized children $(N=533)$ and $57.3 \%(N=718)$ were male. The mean age of hospitalized children was 3.6 years and the mean length of hospital stay was five days. The description of pain intensity was considered by the evaluation instrument applied during the hospitalization period. In addition, the highest score was recorded during the whole evaluation period of the child during hospitalization. There were intense pain in some period of hospitalization, the children evaluated with the FLACC scale, 41.5\%; 67.7\%; FACES, $73.5 \%$ and NIPS, 37.2\%. The FLACC scale was used to assess $73.3 \%$ of the children; the numeric in $21.3 \%$; the FACES in $3.5 \%$ and the NIPS in $5.6 \%$. Of the children hospitalized during the investigation period, $86 \%(\mathrm{~N}=1075)$ had prescribed analgesia in their records. The adoption of non-pharmacological measures for pain relief was $0.48 \%(\mathrm{~N}=6)$. The diagnosis 
"acute pain" was chosen for $30.1 \%(\mathrm{~N}=375)$. Establishing the relationship between the presence of pain and the choice of the "acute pain" diagnosis, it was observed that it was adopted for $53.85 \%(\mathrm{~N}=259)$ of the children who presented pain at some time of hospitalization. The "acute pain" diagnosis was not chosen for $46.1 \%(\mathrm{~N}=$ $222)$ of the children who had pain and was elected to $14.8 \%(N=113)$ of hospitalized children who did not present pain at any time of hospitalization. From the total sample of the survey ( $N=1251$ medical records), $15.5 \%(N=194)$ of reevaluation records were obtained. Conclusion: the frequency of pain in hospitalized children was $38.7 \%$; The children evaluated with self-report scales presented higher pain intensity at some point of hospitalization. The FLACC scale was the most used to evaluate hospitalized children. Non-pharmacological measures for pain relief are infrequent, and pain reevaluation is not performed satisfactorily.

KEYWORDS: Child. Pain measurement. Pediatric nursing. Pain. 


\section{LISTA DE FIGURAS}

Figura 1. Fluxograma de seleção de amostra. São Paulo, 2019. - 32 


\section{LISTA DE GRÁFICOS}

Gráfico 1 - Incidência de Internação por Sexo, segundo registro em prontuários. São Paulo, 2019. - 33

Gráfico 2 - Incidência das Especialidades Diagnósticas, segundo registros em prontuários. São Paulo, 2019. - 34

Gráfico 3 - Período de Internação por Especialidades Diagnósticas, segundo registros em prontuários. São Paulo, 2019. - 35

Gráfico 4 - Frequência de Dor nas Especialidades Diagnósticas, segundo registros em prontuários. São Paulo, 2019. - 36

Gráfico 5 - Frequência de Dor Intensa conforme uso de Instrumentos de Avaliação da Dor, segundo registros em prontuários. São Paulo, 2019. - 37

Gráfico 6 - Frequência do uso de Instrumentos Validados para Avaliação da Dor em Pediatria. São Paulo, 2019. - 38 


\section{LISTA DE QUADROS}

Quadro A - Revisão de literatura. São Paulo, 2019.

Quadro 1 - Descrição de medicamentos prescritos e porcentagem de medicamentos prescritos administrados, segundo registros em prontuários. São Paulo, 2019. - 39

Quadro 2 - Frequência de analgesia realizada conforme especialidade médica, segundo registros em prontuários. São Paulo, 2019 - 40

Quadro 3 - Aplicação de medidas não farmacológicas. São Paulo, 2019. - 43

Quadro 4 - Medidas Não Farmacológicas aplicadas às crianças internadas no HUUSP, segundo registros de prontuários. São Paulo, 2019. - 44

Quadro 5 - Relação entre Presença de Dor e Adoção de Diagnóstico de Enfermagem "Dor Aguda”, segundo registros em prontuários. São Paulo, 2019 - 45 


\section{LISTA DE TABELAS}

Tabela 1. Descrição do uso de medicamentos conforme especialidade médica, segundo registro em prontuários. São Paulo, 2019. - 41 


\section{SUMÁRIO}

1 INTRODUÇÃO 16

2 OBJETIVOS 25

2.1 Objetivo geral 26

2.2 Objetivos específicos 26

3 METODOLOGIA 27

$3.1 \quad$ Tipo de Estudo 28

$3.2 \quad$ Local de Estudo 28

3.3 População e Amostra 28

3.4 Coleta de Dados 29

3.5 Análise de Dados 29

3.6 Aspectos Éticos 30

$4 \quad$ RESULTADOS 31

4.1 Frequência de dor 35

4.2 Intensidade de dor 36

4.3 Frequência do uso de instrumentos para avaliação da dor 37

4.4 Descrição do Uso de Instrumentos para Avaliação da Dor 38

4.5 Descrição das medidas farmacológicas 38 Descrição do uso de medicamentos conforme

4.6 especialidade médica, segundo registro em prontuários 40

4.7 Aplicação de medidas não farmacológicas 43

Diagnóstico de enfermagem relacionado à dor em

$\begin{array}{lll}4.8 & \text { pediatria } & 44\end{array}$

4.9 Reavaliação da Dor 45

5 DISCUSSÃO 46

6 CONCLUSÃO 56

$7 \quad$ LIMITAÇÕES DO ESTUDO 59

$8 \quad$ IMPLICAÇÕES PARA A PRÁTICA CLÍNICA 61

9 CONSIDERAÇÕES FINAIS 63

10 REFERÊNCIAS 65

11 APÊNDICE E ANEXOS 70 
1 INTRODUÇÃO 


\section{INTRODUÇÃO}

A dor, por sua repercussão no estado geral do indivíduo, é de forte interesse mundial. Analisando o relatório da Organização Mundial da Saúde (OMS) sobre as doenças que mais matam no mundo, percebe-se que em algum momento do curso da doença o paciente terá queixas álgicas (OMS, 2012).

A Internacional Association for the Study of Pain (IASP) trabalha para que a avaliação e tratamento da dor sejam considerados aspectos cruciais no atendimento ao paciente com dor aguda ou crônica. Esta instituição visa à construção de políticas e guidelines que norteiam o manejo da dor em todo o mundo e a difusão do conhecimento científico entre as equipes de saúde, o que possibilitará atendimento humanizado e de qualidade.

A Sociedade Brasileira para Estudo da Dor (SBED) afirma que a dor afeta a população causando sofrimento e prejuízos nas atividades de vida diária das pessoas. Um relatório divulgado pela SBED descreve os benefícios no controle da dor não apenas para os pacientes, mas também para as Instituições de saúde, entre eles: redução no tempo de alta da unidade de terapia intensiva ou do hospital; menor custo ao sistema de saúde; menos complicações que exigem tempo da equipe médica e de recursos para a saúde; mais eficiência na utilização de recursos e tempo da enfermagem; melhor satisfação do paciente com o hospital, melhor marketing, e maior reputação do hospital (SBED, 2011).

Mesmo diante de tais benefícios, atualmente os problemas relacionados à avaliação e ao tratamento adequado da dor persistem e comprometem a assistência, inclusive às crianças, fazendo com que elas sofram desnecessariamente (MANOCHA; TANEJA, 2016; THRANE et al., 2016).

Nos pacientes pediátricos, além da complexidade habitual da avaliação da dor, considerando a característica subjetiva, é necessário, também, considerar as fases de desenvolvimento em que se encontra a criança. A OMS (2012) orienta que a manifestação da dor na criança depende da idade, desenvolvimento cognitivo e do contexto sociocultural em que a criança está inserida e, devido a isso, o manejo precisa ser adequado a cada paciente, entendendo manejo como avaliação, intervenção e reavaliação da dor. 
A avaliação de um sintoma subjetivo como a dor requer conhecimento técnico, sensibilidade e tempo para que as intervenções propostas atinjam o objetivo primordial que é alívio da dor. Nesse processo destaca-se a importância da observação de comportamentos não verbais, que podem demonstrar aspectos não citados no questionamento verbal.

A avaliação da criança começa com a investigação da causa da dor, quando é questionado à criança onde se localiza a dor. Um estudo realizado por Herr et al. (2011) destaca a adoção de um instrumento de avaliação que valorize o autorrelato, investigando as causas de dor e observando o comportamento dos pacientes.

Nos casos em que a criança esteja impossibilitada de interagir, seja pela pouca idade ou por limitações cognitivas, pode-se consultar os pais ou cuidadores principais. Nesse contexto, as mães têm papel ativo na investigação da dor em crianças jovens e inconscientes, e as queixas podem ser reportadas pelas mães aos enfermeiros (AZIZNEJADROSHAN; ALHANI; MOHAMMADI, 2016).

Os instrumentos de avaliação são aplicados para obtenção de um score e deverão considerar a localização, intensidade e qualidade da dor. As escalas para mensurar a dor podem ser unidimensionais ou multidimensionais. As unidimensionais, por exemplo, a Escala de FACES (WONG; BAKER, 1987) e a Escala Numérica mensuram apenas uma dimensão da dor, a intensidade. Enquanto as multidimensionais avaliam características e aspectos emocionais, como o Inventário para Avaliação da Dor McGill (MELZACK, 1975).

A escala FLACC (Face, Legs, Activity, Cry, Consolability) (MERKEL,1997) "inclui cinco categorias de comportamento: expressão facial $(F)$, movimentos de pernas (L), atividade (A), choro (C) e consolabilidade (C). Ela avalia a dor quantificando comportamentos associados à dor" (HOCKENBERRY; WILSON, 2014, p. 143). Dessa forma também é estruturada a escala NIPS (Neonatal Infant Pain Scale) (ALCOCK; DULBERG, 1993) que é um instrumento de avaliação da dor adotado para recém-nascidos.

A avaliação por meio de instrumentos de autorrelato engloba escalas como a de FACES e a Escala Numérica. Elas são utilizadas com crianças que conseguem verbalizar sua dor, ou ainda, crianças que são capazes de relacionar a intensidade 
da sua dor com as faces ou fazer correspondência com os valores da escala numérica.

A partir das duas opções citadas acima, dependendo da idade, da capacidade cognitiva e de experiências anteriores, a criança é capaz de relacionar a sua dor às expressões faciais e valores numéricos no momento da avaliação.

Independente do instrumento utilizado para a avaliação da dor da criança, o primordial é que este possibilite ao profissional a construção de um plano de intervenções que atenda individualmente cada criança. O conhecimento técnico da equipe é essencial para a realização de avaliações criteriosas de dor.

As instituições de saúde empenhadas com o manejo da dor investem fortemente em políticas específicas para o treinamento dos profissionais e desenvolvem rotinas e padrões no atendimento aos pacientes.

A adoção de protocolos e guidelines favorece o manejo da dor na criança, considerando que eles estabelecem as melhores práticas no atendimento a uma determinada população. Protocolos que são construídos a partir de discussões com a equipe de saúde, em que os pontos importantes de conduta são debatidos e o processo reflexivo acontece, tendem a fazer com que os indivíduos responsáveis pela prática mostrem-se realmente envolvidos.

Esses protocolos de atendimento contêm todo o fluxo de ações para o atendimento da criança com dor. Com a intenção de aprimorar o atendimento aos pacientes com dor, as instituições de saúde também podem aderir aos serviços de acreditação, como a Joint Comission, que adota a dor como $5^{\circ}$ sinal vital.

Em uma de suas recomendações sobre o manejo da dor, a Joint Comission determina que sejam identificados líderes ou equipes de liderança responsáveis pelo manejo da dor e pela prescrição segura de opioides; envolver os pacientes no desenvolvimento de seu plano de tratamento criando metas; promover o uso seguro de opioides identificando pacientes de risco; monitorar pacientes de risco; facilitar o acesso clínico para prescrições e monitorar os dados de programas; promover atividades focadas na avaliação e manejo da dor aumentando a segurança e qualidade para os pacientes (BAKER, 2017).

Resultados de um estudo descrevem que após a implantação de uma política direcionada aos pacientes com dor, as avaliações aumentaram sensivelmente, 
assim como os registros das avaliações. Atrelado a isso observaram um número menor de crianças com dor intensa, comparado ao período em que não havia política implantada (ZHU et al., 2012).

Após uma década de trabalho realizado em um hospital francês com a implantação de políticas específicas direcionadas ao paciente com dor, traçou-se um perfil dos pacientes atendidos, da prevalência e das causas mais frequentes de dor. Esse estudo evidenciou que a diminuição das queixas álgicas está relacionada ao envolvimento de médicos e enfermeiros no cuidado do paciente, incluindo o empenho para reavaliação da dor (BOURDILLON et AL., 2012).

As estratégias Evidence-Based Practice for Improving Quality (EPIQ) e Knowledge Translation (KT) adotadas por instituições de saúde no Canadá, promovem a transferência do conhecimento teórico sobre a avaliação e o manejo da dor para a prática dos profissionais de saúde. Após a adoção dessas estratégias, a intensidade de dor observada nas crianças hospitalizadas diminuiu, comparada ao cuidado padrão oferecido a elas. Além disso, o estudo avaliou a influência do contexto organizacional e a relação entre o uso da pesquisa, a avaliação criteriosa da dor e os resultados clínicos, mostrando que existe a dificuldade para tomada de decisão entre os profissionais mais novos (YAMADA et al., 2017).

A intervenção Booster, também aplicada em instituições do Canadá, consiste em um treinamento com sessões para líderes no manejo da dor pediátrico, com a intenção de manter a constância na qualidade da avaliação e manejo. No entanto, os resultados mostraram que a sustentabilidade das ações para o manejo da dor é complexa e pouco compreendida (STEVENS et AL., 2017).

Ainda no contexto internacional, o hospital Johns Hopkins Children's Center conta com uma política de atendimento à criança com dor, que é avaliada por um grupo de especialistas, garantindo que a avaliação seja feita e registrada em $100 \%$ dos casos atendidos, evidenciando, portanto, o benefício de contar com uma equipe treinada (KOZLOWSKI et al., 2014).

Contudo, esse estudo evidenciou, também, que mesmo com as políticas bem implantadas e contando com a acreditação da Joint Comission, nem todos os profissionais de saúde realizam a avaliação da dor como preconizado. Falhas na 
comunicação foram identificadas como um fator prejudicial na relação entre a equipe de saúde, a criança e sua família (KOZLOWSKI et al., 2014).

Alguns estudos mostram que a comunicação ineficiente promove insegurança na família, não estabelecendo uma relação de confiança e parceria com a equipe de saúde, que, por sua vez, perde informações preciosas sobre o comportamento da criança, prejudicando a avaliação e o manejo da dor (HABICH et al., 2012; SIEW et al., 2011; JONGUDOMKARN et al., 2012; HUI et al., 2015; TWYCROSS; COLLINS, 2013; OLSHANSKY et AL., 2015).

Por outro lado, o suporte dado pela enfermagem com informações sobre o cuidado auxilia os pais no processo de hospitalização, fazendo com que relatem a dor da criança e solicitem a analgesia prescrita disponível (SIEW et al., 2011).

As crianças relatam que precisam melhorar a comunicação com seus enfermeiros. Além disso, existem casos em que a enfermagem não valida a informação da família referente à dor da criança, nem quando solicita medicação para alívio da dor (TWYCROSS; COLLINS, 2013).

Outro fator que dificulta a avaliação e manejo da dor da criança é a ausência de alterações fisiológicas. A criança pode ficar desacreditada e seus relatos e comportamentos não serem valorizados, ocasionando um julgamento por parte da equipe de saúde. Nesses casos a dor da criança pode ser subestimada. (TWIGG; BYRNE, 2014).

Quando os enfermeiros reportam seu trabalho por meio de questionários e entrevistas há diferença da conduta na prática. Apesar de teoricamente admitirem que $\mathrm{o}$ autorrelato seja a maneira mais eficiente de avaliar, buscam indicadores clínicos de dor durante a avaliação (LAFOND et al., 2016).

A crença do profissional em buscar sinais clínicos indicativos de dor durante a avaliação pode comprometer a oferta de medidas farmacológicas e não farmacológicas para o alívio da dor.

Enfermeiros têm uma função maior na avaliação e manejo da dor de crianças hospitalizadas. Expandir o conhecimento com o qual acessam os instrumentos validados para avaliação da dor, usando intervenções baseadas em evidência, promove uma base compreensiva para prática (YAMADA et al., 2017). 
Os resultados de pesquisas podem ser um guia para enfermeiros entenderem que o relacionamento cordial com crianças e seus pais, associado ao relacionamento profissional, é um importante fator que afeta o manejo da dor em crianças. O empenho da enfermagem em realizar pesquisas no estudo da dor, divulgando as principais áreas de investigação nesse tema reflete a preocupação com a qualidade assistencial e exibe o comprometimento no foco de assistência que é o paciente (OLIVEIRA et al., 2014; AZIZNEJADROSHAN; ALHANI; MOHAMMADI, 2016).

Dentro da equipe de saúde, a enfermagem desempenha papel de relevância, sendo o grupo que passa mais tempo ao lado do paciente, prestando assistência direta, responsável pelo maior número de avaliações de dor nas instituições.

Estudo realizado mostra que o registro de avaliação de dor, feito com instrumento validado, pela equipe de enfermagem, é visto em $96 \%$ de todos os prontuários auditados. Em contrapartida a avaliação da dor, de forma descritiva, realizada pela enfermagem, é encontrada em $48 \%$ dos prontuários analisados, enquanto os profissionais médicos documentam menos de $5 \%$ das avaliações descritivas de dor (KOZLOWSKI et al., 2014).

A equipe de enfermagem realiza intervenções farmacológicas prescritas e não farmacológicas para alívio da dor, podendo ser responsável direta pelo processo de reavaliação da dor. Além disso, é a equipe que estabelece o elo entre o paciente e sua família com todos os membros da equipe e, também entre os membros de todas as equipes, compartilhando informações para a condução do manejo da dor.

O registro sobre medidas não farmacológicas em geral não é encontrado nas auditorias de prontuários. Imagina-se que elas são realizadas, mas os registros são precários (ZHU et al., 2012; FRIEDRICHSDORF et al., 2015).

Estratégias como distração, participação dos pais e cuidadores, conforto da criança e posicionamento foram apontadas ser mais efetivas que medidas analgésicas, reconhecidas por pais e pacientes (FRIEDRICHSDORF et al., 2015).

A adoção de medidas não farmacológicas pode acontecer em vários setores do hospital, tanto internação, pacientes crônicos e atendimento de emergência. Um hospital na Coreia adota medidas de distração para crianças submetidas a 
procedimento de sutura. $O$ resultado demonstrou que a distração com recurso audiovisual foi efetiva na redução da dor (YOUNG; HEE, 2013).

Medidas como massagens ou terapias de toque, para lactentes, têm resultado positivo na redução dos índices de dor (LINHARES et al., 2012) e, infelizmente, dependendo da política adotada pela Instituição nem sempre é possível oferecer ao paciente. É indicado também que ambas as medidas de alívio (farmacológicas e não farmacológicas) possam ser oferecidas (CHILD LIFE SERVICES, 2014).

Um trabalho realizado no Brasil relata a baixa adesão de medidas não farmacológicas pelas equipes médica e de enfermagem. De qualquer maneira, essas ações podem e devem ser amplamente difundidas pela equipe de saúde em geral, já que os benefícios são comprovados. (LINHARES et al., 2012).

Um aspecto importante das práticas complementares é o suporte emocional dado à criança e aos pais. Ele ajuda a estrutura familiar a se manter e promove o desenvolvimento de estratégias que sejam exequíveis pela própria família, além de auxiliar na tomada de decisão conjunta e a segurança para a extensão do cuidado no domicílio.

Reavaliar as crianças após intervenções para alívio da dor é o mais importante aspecto do manejo da dor porque irá demonstrar a eficácia do plano de tratamento e consequentemente, a necessidade de mudança para proporcionar alívio adequado.

A reavaliação da dor dos pacientes e constatação da eficácia das intervenções adotadas ainda é um desafio para a equipe de saúde como um todo e, em especial, para enfermagem, que necessita aprimorar estratégias de reavaliação, visto que é responsável pela adequação do plano de cuidados ( $\mathrm{HABICH}$ et al., 2012).

A expertise dos enfermeiros no manejo da dor pode ser a chave para as melhores práticas, mas desempenhar essa função exige que os enfermeiros estejam em constante processo de aprimoramento (RAMIRA; INSTONE; CLARK, 2016). A realização de boas práticas só acontecerá mediante conhecimento técnico-científico sobre dor, técnicas de comunicação e esforço diário para manter a constância nesse processo. 
Embora estudos sobre dor em pediatria tenham sido produzidos com a intenção de melhorar o manejo da dor, infelizmente, pouco foi transposto para a prática. A avaliação como ponto inicial do manejo precisa ser realizada de modo criterioso, exigindo do profissional que a realiza, técnica e desprendimento de julgamentos com relação à criança. (TWIGG; BYRNE, 2014).

$\mathrm{Na}$ instituição, local de pesquisa, a avaliação da dor dos pacientes pediátricos é iniciada no momento em que a criança é admitida na retaguarda de prontosocorro, embora não existam protocolos de atendimento das crianças com dor.

Essa estrutura de trabalho fragmenta dados importantes a respeito da criança, prejudicando a tomada de decisão do enfermeiro em relação ao manejo da dor.

Estudo composto por pré e pós-teste realizado em 2013 teve como objetivo avaliar o conhecimento técnico da equipe de enfermagem sobre o manejo da dor, após treinamento específico sobre o tema. $O$ resultado obtido demonstrou aumento do conhecimento técnico da equipe nas seguintes temáticas: termos técnicos e escalas, escada analgésica, medidas não farmacológicas de intervenção e reavaliação, entre outras. (CARNEIRO; PINTO, 2013).

Embora existam pesquisas realizadas abordando a temática do manejo da dor em pediatria, não foram encontrados estudos na literatura que identificassem como é realizado o manejo da dor nas crianças internadas na Instituição local desta pesquisa.

Conhecer a maneira como as crianças com dor nessa Instituição são avaliadas é primordial para 0 atendimento de qualidade e fundamental para 0 aprimoramento de estratégias para um manejo adequado da dor.

Nesse sentido, este estudo consiste em identificar a incidência de dor, a maneira como é realizada sua avaliação e quais as ações adotadas para alívio da dor, por meio da análise dos registros realizados pela equipe de enfermagem.

Com o intuito de avançarmos no conhecimento sobre manejo da dor em pediatria, este estudo tem como pergunta:

"Como é realizado o manejo da dor nas crianças internadas em um Hospital Escola do município de São Paulo"? 
2 OBJETIVOS 


\section{OBJETIVOS}

\subsection{OBJETIVO GERAL:}

Identificar como é realizado o manejo da dor em crianças internadas, mediante análise de registro em prontuários.

\subsection{OBJETIVOS ESPECÍFICOS:}

- Idenificar a frequência da dor das crianças internadas;

- Identificar a intensidade da dor das crianças internadas;

- Descrever a aplicação dos instrumentos adotados para a avaliação de dor das crianças internadas;

- Descrever as medidas farmacológicas e não farmacológicas adotadas para o alívio da dor das crianças internadas;

- Verificar a prevalência de diagnóstico de Enfermagem, relacionado à dor, para as crianças internadas;

- Identificar a reavaliação da dor das crianças internadas. 
3 METODOLOGIA 


\section{METODOLOGIA}

\subsection{TIPO DE ESTUDO}

Trata-se de um estudo retrospectivo, de abordagem quantitativa, realizado mediante análise de registros em prontuários de crianças internadas em um Hospital Escola do Município de São Paulo, no período de julho/16 a julho/17.

\subsection{LOCAL DE ESTUDO}

O estudo foi realizado em um Hospital Escola do Município de São Paulo de nível secundário, composto por 178 leitos, que atende população adulta e pediátrica. A pesquisa foi realizada a partir dos prontuários de todos os pacientes internados no período de um ano e que transitaram entre os setores: retaguarda de pediatria, enfermaria pediátrica e unidade de terapia intensiva pediátrica.

A missão da Instituição é desenvolver atividades de ensino e pesquisa na área da saúde e assistência hospitalar. Sua visão e valores estão relacionados a ampliar o desenvolvimento de atividades que sirvam de modelo para outros serviços, assim como integrar todo o processo de atendimento de saúde, com ênfase nos recursos humanos do hospital.

\subsection{POPULAÇÃO E AMOSTRA}

A população foi composta por 1728 prontuários, caracterizando todas as internações de crianças com idades de 28 dias a 14 anos completos, no período de julho/16 a julho/17. A amostra compreendeu 1252 prontuários de crianças internadas em um Hospital Escola do Município de São Paulo.

Critérios de Inclusão - todos os prontuários de crianças com idade entre 28 dias e 14 anos completos, internadas em um Hospital Escola do Município de São Paulo, no período de julho/16 a julho/17. 
Critérios de exclusão - prontuários não fornecidos pelo Serviço de Arquivo Médico e Estatístico (SAME), por uso em consultas ou reinternações; prontuários incompletos ou sendo usados por outros pesquisadores.

\subsection{COLETA DE DADOS}

A pesquisa foi realizada por meio da consulta e análise dos registros de prontuários das crianças internadas no período de julho/16 a julho/17.

A coleta dos dados ocorreu no período de 12/09/17 a 17/07/18. Os prontuários foram solicitados no setor SAME e liberados para consulta no mesmo local.

No caso em que as crianças apresentaram mais de uma internação no período estabelecido, foram considerados os registros da internação mais recente para coleta de dados.

Para a coleta foi elaborado um instrumento (Apêndice 1) para anotação dos registros composto por dados demográficos, dados da internação e informações a respeito dos aspectos relacionados a dor durante o período de internação.

Os impressos de prontuários consultados nessa pesquisa foram: capa de prontuário, impresso institucional de registro da avaliação da dor (usado para avaliação da dor no Departamento Materno Infantil); anotação de enfermagem; prescrição médica e instrumento usado para registro de sistematização da assistência de enfermagem (SAE) adotado pela instituição.

Foi coletado o registro (score) de maior intensidade de dor durante o período de internação, considerando a escala específica adotada para avaliação de cada criança.

Para que os dados de diferentes escalas se tornassem comparáveis, o maior score registrado foi dividido pelo valor máximo da escala correspondente (respeitando a variação de cada escala), segundo orientação estatística. 


\subsection{ANÁLISE DOS DADOS}

Todos os dados das fichas foram armazenados em planilha Microsoft Office Excel® e posteriormente analisados com o programa estatístico R3.5.3.

As variáveis foram analisadas com estatística descritiva (frequências absoluta e relativa). Para a análise das associações entre as variáveis independentes e dependentes, foram aplicados os testes de Pearson's, teste Chi-squared, teste de Kruskal-Wallis rank sum teste de Kruskal-Wallis chi-squared e Teste Exato de Fischer. O nível de significância estatística adotado foi de 5\%.

\subsection{ASPECTOS ÉTICOS}

O presente estudo fundamenta-se na Resolução 466, de 12 de dezembro de 2012, que regulamenta a pesquisa envolvendo seres humanos, conforme determinação do Conselho Nacional de Saúde, do Ministério da Saúde.

O projeto de pesquisa foi encaminhado e aprovado pelos Comitês de Ética da Escola de Enfermagem da Universidade de São Paulo - processo № 2.240 .511 (anexo 2) e do Hospital Universitário da Universidade de São Paulo - processo no 2.277.191 (anexo 3). 
4 RESULTADOS 


\section{RESULTADOS}

A seguir, será descrito qual o perfil das crianças atendidas, assim como a frequência e intensidade da dor, a incidência do uso de instrumentos validados para avaliação das crianças com dor, as medidas de alívio oferecidas às crianças com dor e a incidência de reavaliação da dor. Ainda será exposta a relação entre a frequência de dor com os diagnósticos de Enfermagem relacionados ao cuidado da criança com dor, aplicados durante período de internação, segundo análise dos registros em prontuários, considerando a premissa do estabelecimento do plano de cuidados mais apropriado para cada criança internada durante o período de coleta de dados.

No período de jul/16 a jul/17, foram registradas 1728 internações em um Hospital Escola do Município de São Paulo, resultando, portanto, em 1728 prontuários de crianças internadas. Dessa população os resultados representam uma amostra de 1251 prontuários de crianças internadas.

\section{Fluxograma}

POPULAÇÃO

1728 prontuários
Prontuários não disponibilizados para pesquisa por uso em consultas; reinternações; usados por outros pesquisadores e prontuários incompletos (477 prontuários)

\section{AMOSTRA}

1251 prontuários 
Dentre os pacientes internados $42,6 \%(\mathrm{~N}=533)$ eram do sexo feminino, e $57,3 \%(\mathrm{~N}=718)$ eram do sexo masculino, com média de idade de 3,6 anos. A média de internação dessas crianças foi de cinco dias. (Gráfico 1).

\section{Gráfico 1 - Incidência de Internação por Sexo, segundo registro em prontuários. São Paulo, 2019.}

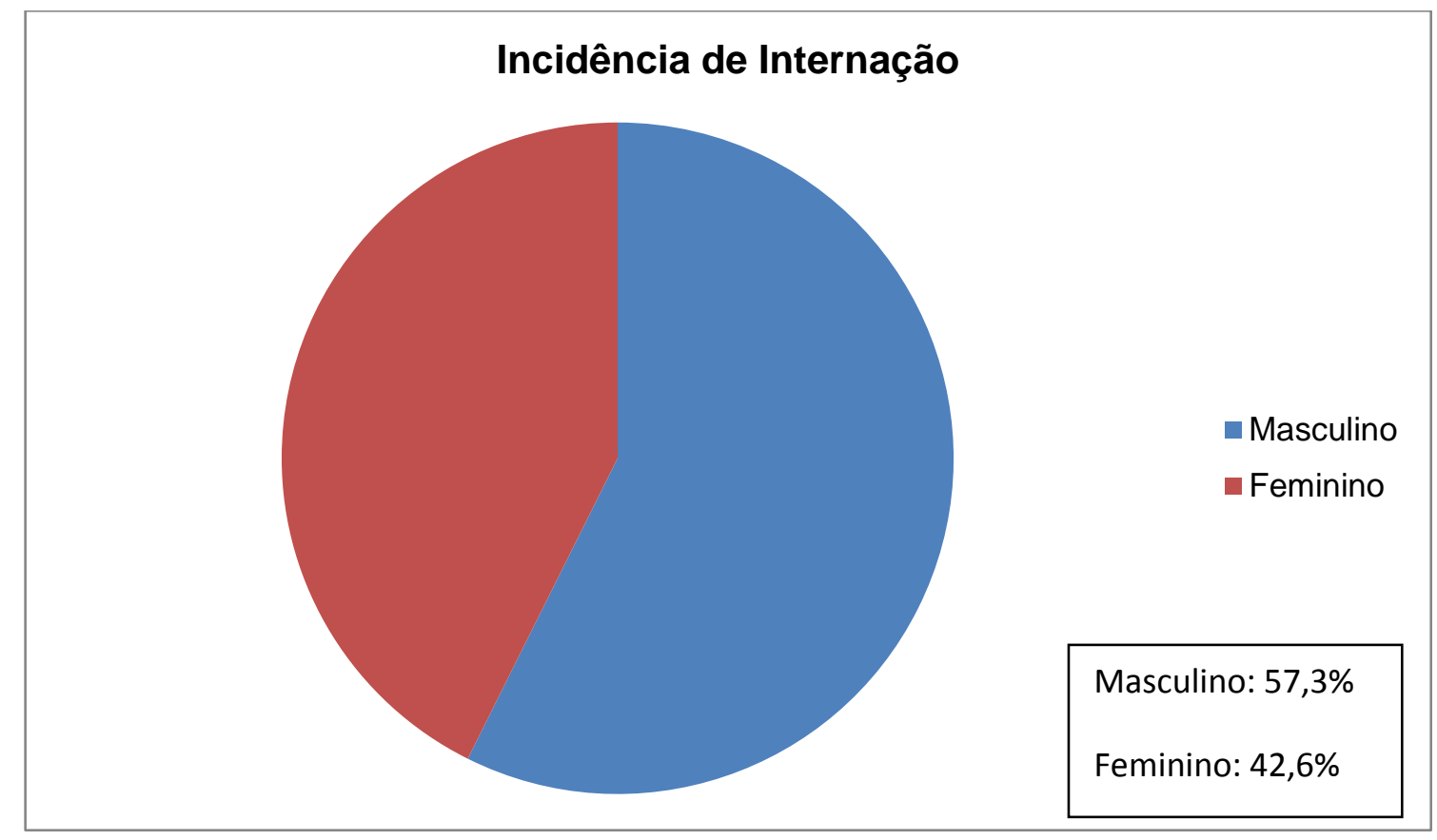

Os diagnósticos médicos foram agrupados por semelhança, constituindo 11 categorias diagnósticas, de acordo com as especialidades. São elas: 1 - afecções respiratórias (pneumonias, bronquite, bronquiolite, crise asmática); 2 - afecções cirúrgicas (todos os pacientes submetidos a procedimentos cirúrgicos); 3 - afecções ortopédicas (todos os pacientes acompanhados pela ortopedia); 4 - afecções metabólicas (diabetes); 5 - afecções neurológicas (traumatismo intra craniano); 6 afecções nefrológicas (distúrbio renais); 7 - afecções otorrinolaringológicas (todos os pacientes acompanhados pela equipe especializada); 8 - afecções infecciosas (pacientes com moléstias infecciosas); 9 - afecções gástricas (GECA); 10 afecções hematológicas (anemia falciforme); 11 - outras afecções.

Considerando essa divisão, a prevalência de internação nessas especialidades foi: afecções cirúrgicas - 16,8\% ( $N=209)$; afecções gástricas - 2,3\% $(\mathrm{N}=29)$; afecções metabólicas - 1,1\% ( $N=14)$; afecções hematológicas - 1,6\% 
$(\mathrm{N}=20)$; afecções infecciosas - 3,1\% (N=39); afecções nefrológicas - 2,6\% $(\mathrm{N}=33)$; afecções neurológicas - 2,2\% (N=28); afecções ortopédicas - 3,8\% ( $N=48)$; afecções otorrinolaringológicas - 1,6\% ( $\mathrm{N}=21)$; afecções respiratórias - 61,4\% $(\mathrm{N}=762)$ e outras afecções - 3,0\% (N=38). (Gráfico 2).

Gráfico 2 - Incidência das Especialidades Diagnósticas, segundo registros em prontuários. São Paulo, 2019.

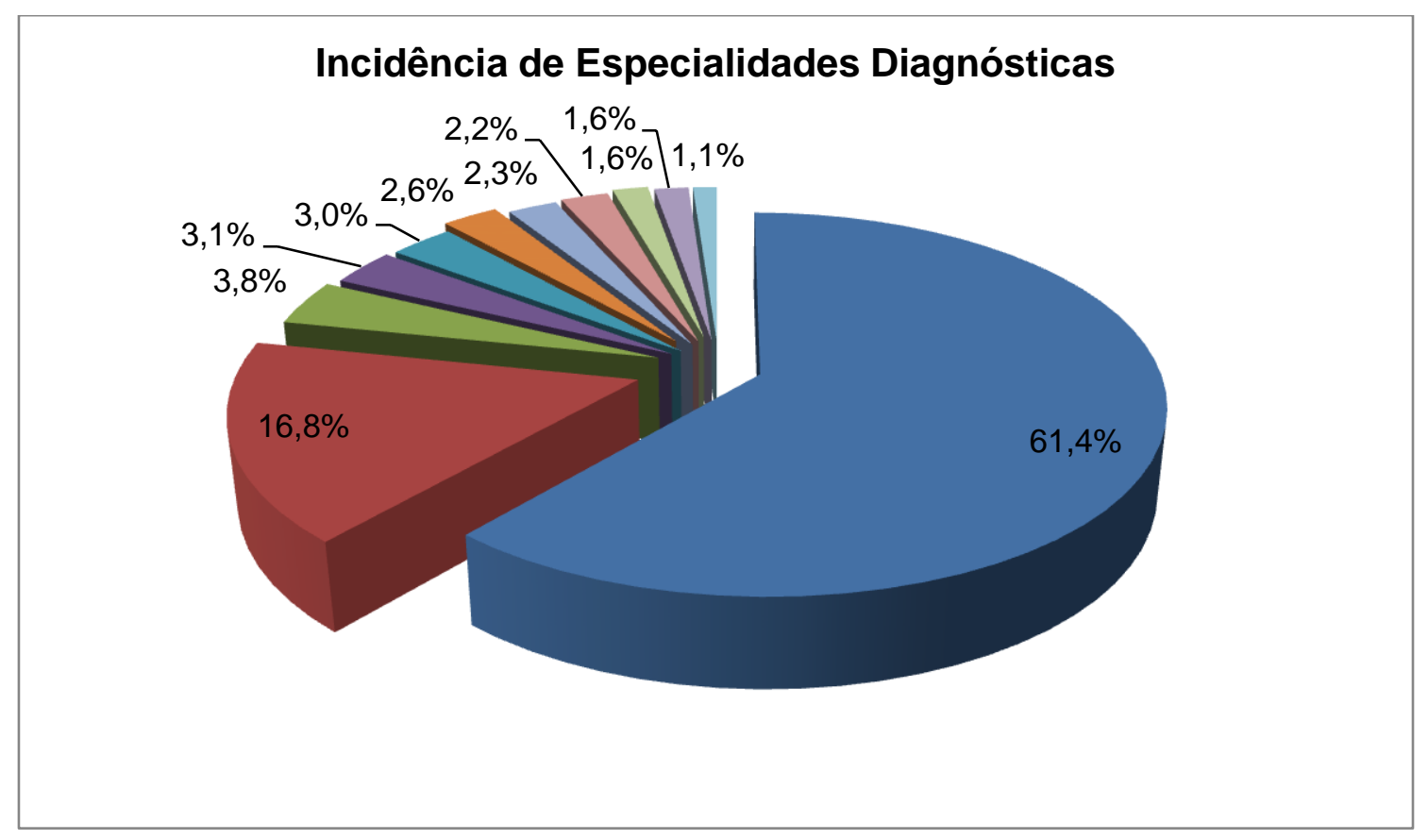

Ainda nos grupos diagnósticos, a média de dias de internação variou em, no mínimo três e no máximo 10 dias, distribuída da seguinte forma: afecções cirúrgicas - 5,52 dias; afecções respiratórias - 4,68 dias; afecções gástricas - 4,41 dias; afecções metabólicas - 8,21 dias; afecções hematológicas - 3,40 dias; afecções infecciosas - 7,36 dias; afecções nefrológicas - 3,97 dias; afecções neurológicas 5,46 dias; afecções ortopédicas - 3 dias; afecções otorrinolaringológicas $-4,57$ dias e outras afecções- 10 dias. (Gráfico 3). 
Gráfico 3 - Período de Internação por Especialidades Diagnósticas, segundo registros em prontuários. São Paulo, 2019.

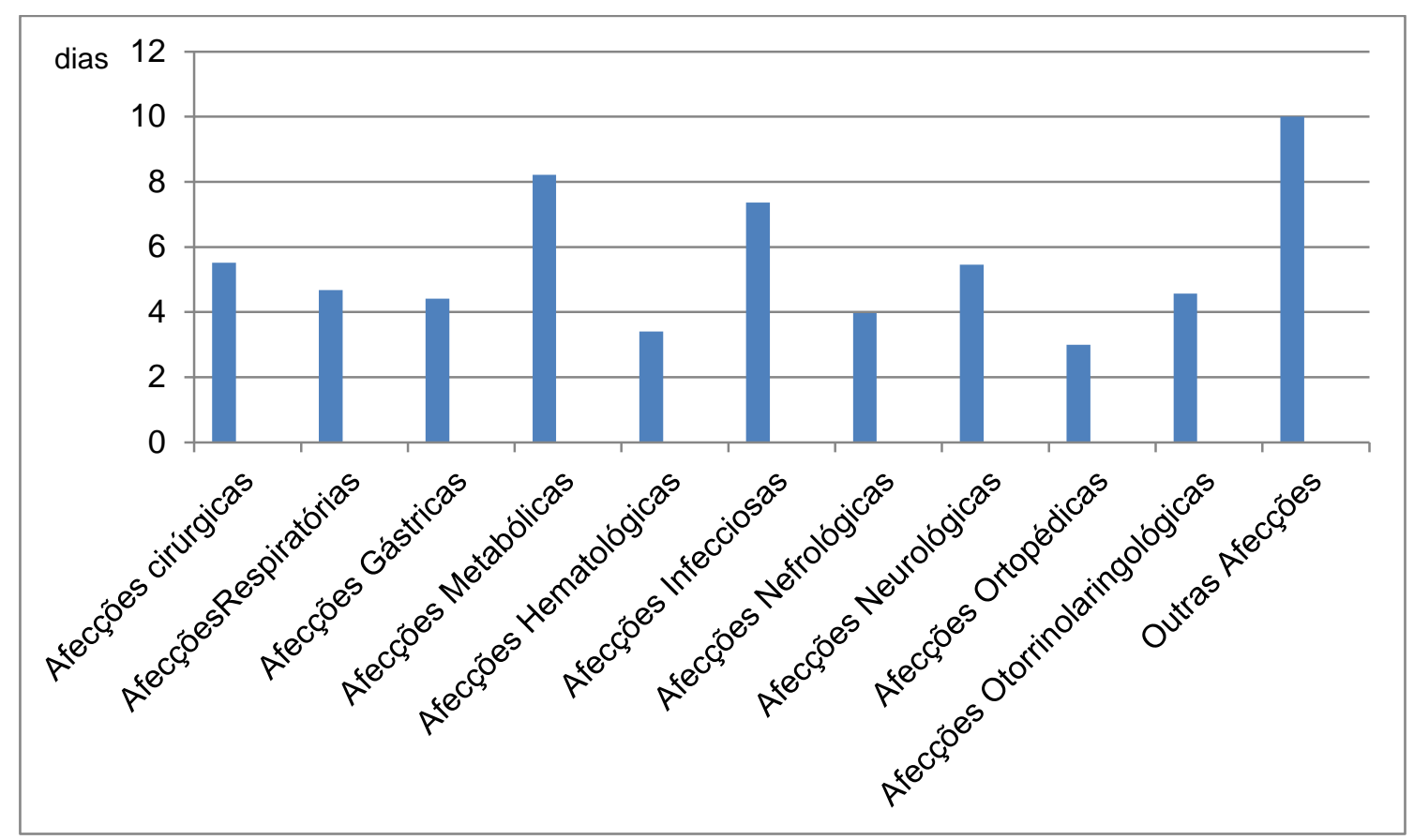

\subsection{FREQUÊNCIA DE DOR}

Dentro da amostra do estudo de 1251 prontuários de crianças internadas, $38,7 \%$ ( $N=481)$ apresentaram dor em algum momento da internação, considerando que $99,55 \%$ desses pacientes foram avaliados de maneira sistemática por meio de instrumentos validados.

Distribuindo a ocorrência de dor nas especialidades diagnósticas já citadas nota-se que a incidência de dor em cada uma delas foi: afecções cirúrgicas $(57,4 \%)$; afecções gástricas (62,0\%); afecções metabólicas (42,8\%); afecções hematológicas (55,0\%); afecções infecciosas (41,0\%); afecções nefrológicas $(57,5 \%)$; afecções neurológicas (42,8\%); afecções ortopédicas $(62,5 \%)$; afecções otorrinolaringológicas (55\%); outras afecções (40,5\%) e afecções respiratórias (29,2\%). (Gráfico 4). 
Gráfico 4 - Frequência de Dor nas Especialidades Diagnósticas, segundo registros em prontuários. São Paulo, 2019.

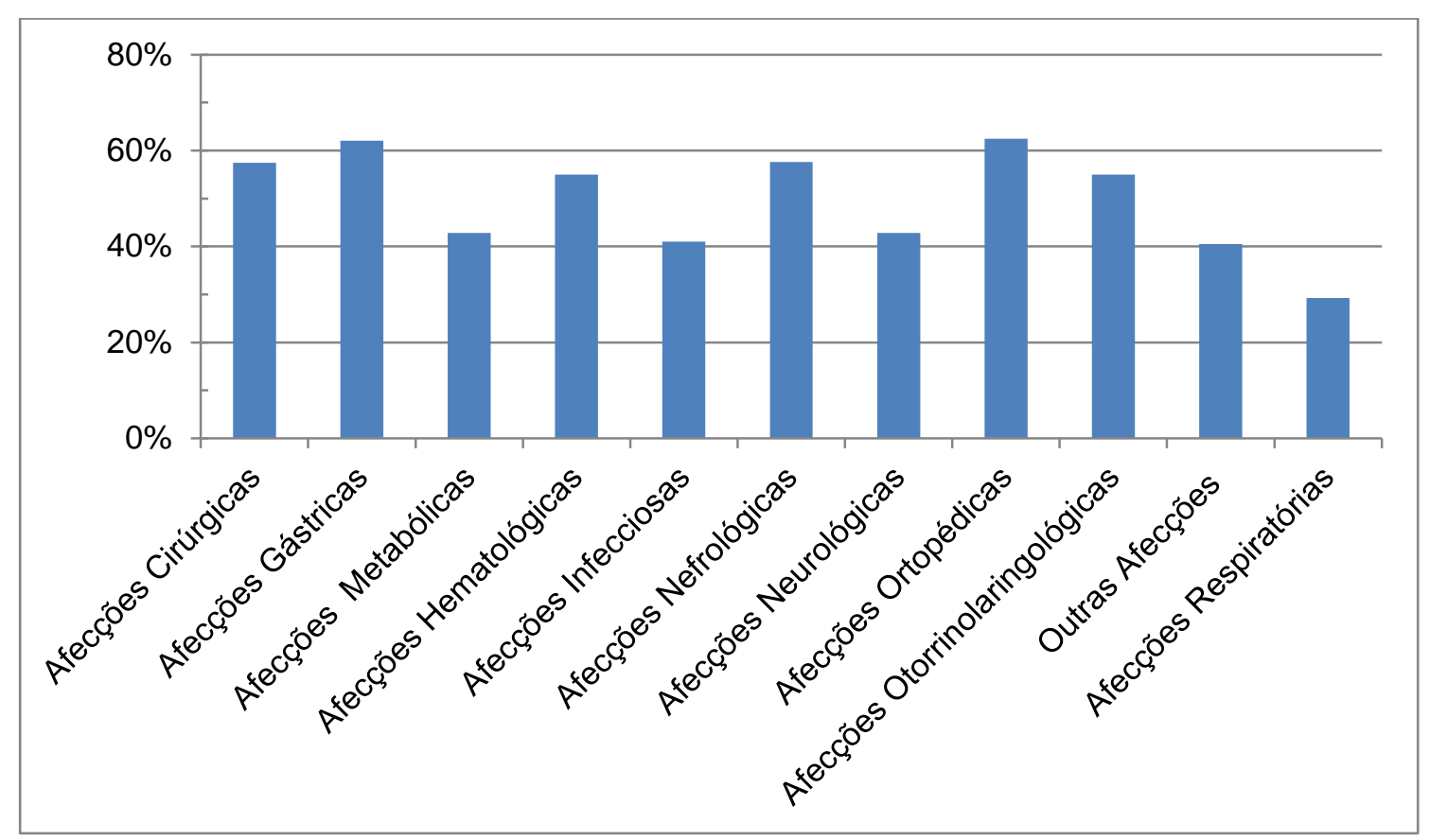

\subsection{INTENSIDADE DE DOR}

A descrição da intensidade da dor foi considerada pelo instrumento de avaliação aplicado durante o período de internação. Além disso, foi considerado o registro de maior score dentro de todo o período de avaliação da criança durante a internação. Das crianças avaliadas com a escala FLACC, 41,5\% apresentaram dor intensa em algum período da internação; das crianças avaliadas com escala numérica, 67,7\% apresentaram dor intensa durante a internação; das crianças avaliadas com escala FACES, 73,5\% apresentaram dor intensa e das crianças avaliadas com escala NIPS, 37,2\% apresentaram dor intensa em algum período da internação. (Gráfico 5). 
Gráfico 5 - Frequência de Dor Intensa conforme uso de Instrumentos de Avaliação da Dor, segundo registros em prontuários. São Paulo, 2019.

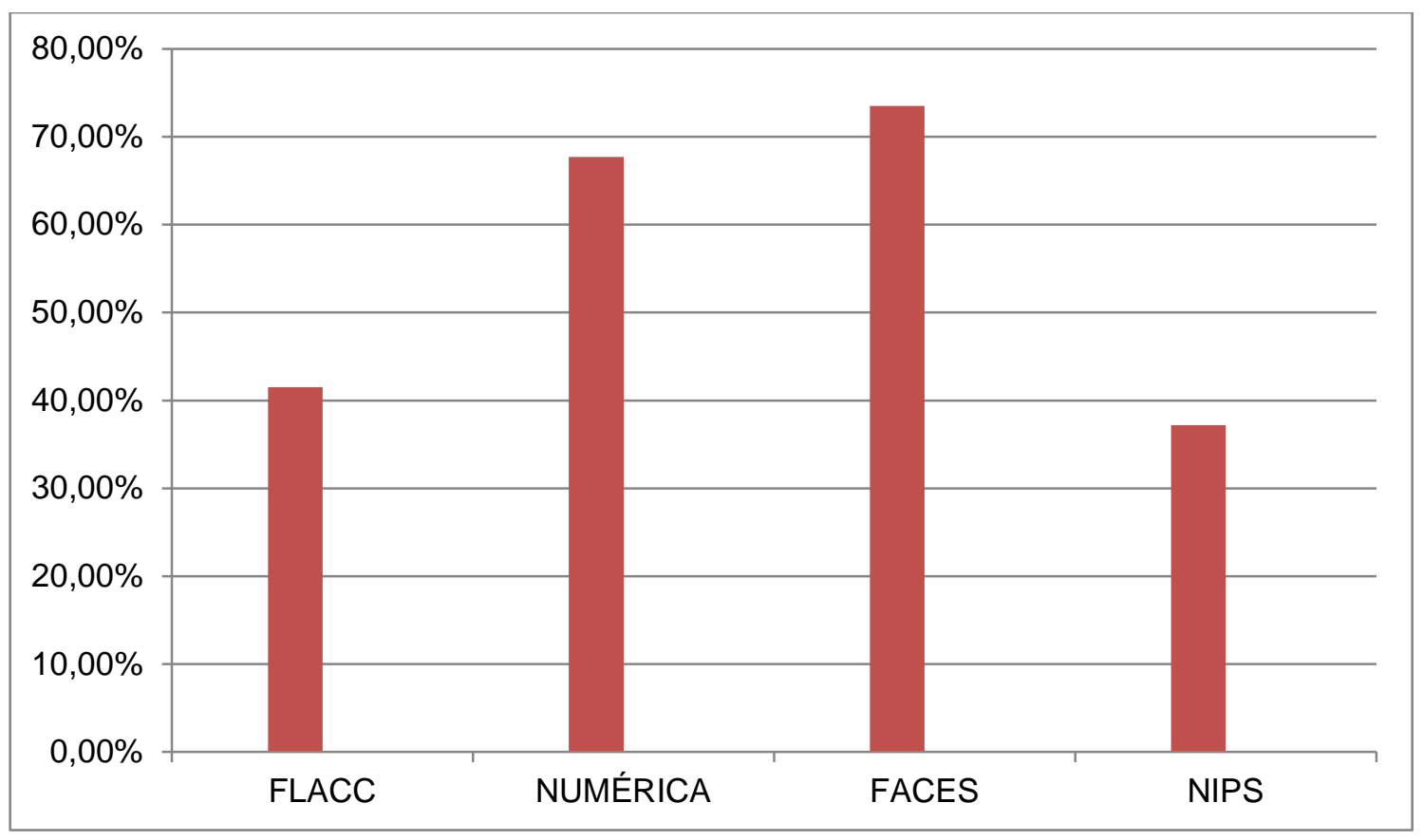

\subsection{FREQUÊNCIA DO USO DE INSTRUMENTOS PARA AVALIAÇÃO DA DOR}

Os pacientes internados em um Hospital Escola do Município de São Paulo foram avaliados sistematicamente com instrumentos validados e dentre eles seu uso sofreu a seguinte variação: a escala FLACC foi usada para avaliar $73,3 \%$ das crianças; a escala numérica foi usada em $21,3 \%$ dos casos; a escala FACES foi usada em $3,5 \%$ das crianças internadas e a escala NIPS foi usada em $5,6 \%$ das crianças internadas (Gráfico 6). 


\section{Gráfico 6 - Frequência do uso de Instrumentos Validados para Avaliação da}

Dor em Pediatria, São Paulo, 2019.

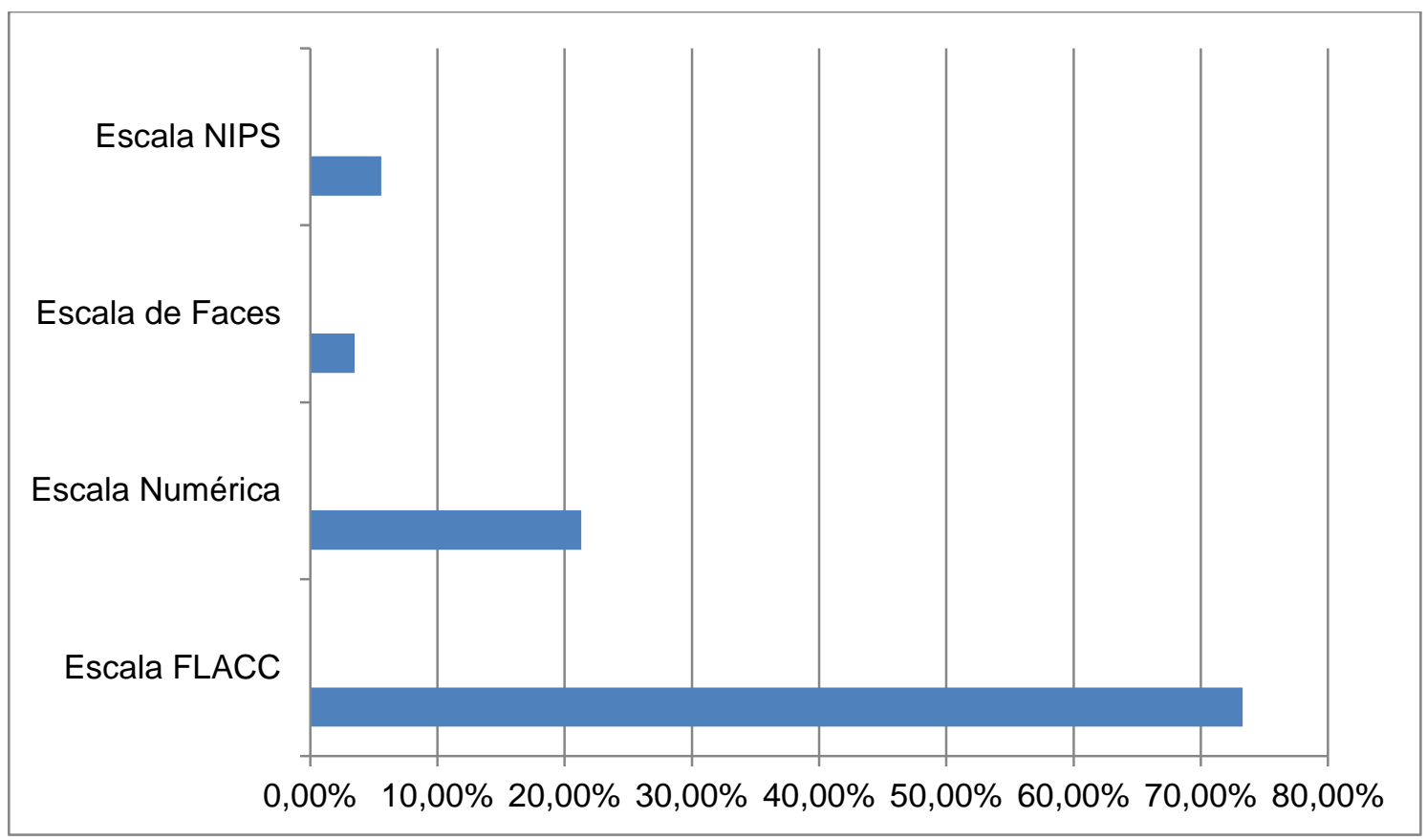

\subsection{DESCRIÇÃO DO USO DE INSTRUMENTOS PARA AVALIAÇÃO DA DOR}

No presente estudo as crianças sofreram avaliação de dor com instrumentos validados, conforme descrição acima. No entanto, foi possível detectar casos em que as crianças receberam avaliações durante o mesmo período de internação, com instrumentos diferentes. Da amostra de 1251 prontuários analisados, dentre os dados obtidos, 13 crianças não receberam avaliação com nenhum tipo de instrumento validado; 1172 crianças foram avaliadas com um instrumento validado durante todo período de internação; um total de 55 crianças foi avaliado com dois instrumentos validados durante período de internação e três crianças foram avaliadas com três instrumentos validados durante todo o período de internação. 


\subsection{DESCRIÇÃO DAS MEDIDAS FARMACOLÓGICAS}

Das crianças internadas no período investigado, 86\% ( $\mathrm{N}=1075)$ tinham em seu prontuário analgesia prescrita. Esse dado considera as prescrições para analgesia de horário e também os casos de prescrição $S / N$ e ACM. Os dados revelam o uso de medicamentos administrados para analgesia e sua incidência no período descrito, conforme quadro abaixo.

Quadro 1 - Descrição de medicamentos prescritos e porcentagem de medicamentos prescritos administrados, segundo registros em prontuários. São Paulo, 2019.

\begin{tabular}{|l|l|}
\hline MEDICAMENTO & $\begin{array}{l}\text { \% REALIZAÇÃO DE MEDICAÇÃO } \\
\text { PRESCRITA }\end{array}$ \\
\hline Dipirona & 81,20 \\
\hline Paracetamol & 17,10 \\
\hline Cetoprofeno & 8,20 \\
\hline Tramal & 6,24 \\
\hline Ibuprofeno & 3,20 \\
\hline Morfina & 1,44 \\
\hline Cetorolaco & 3,28 \\
\hline Xilocaína spray & 0,16 \\
\hline Codeína & 0,16 \\
\hline Simeticona & 0,08 \\
\hline Buscopan & 0,08 \\
\hline Xilocaína gel & 0,08 \\
\hline Dolantina & 0,08 \\
\hline Gabapentina & 0,16 \\
\hline
\end{tabular}

Dentro dos dados referentes à analgesia prescrita foi possível identificar qual especialidade médica exigiu maior frequência de analgesia para as crianças internadas, conforme quadro a seguir. 
Quadro 2 - Frequência de analgesia realizada conforme especialidade médica, segundo registros em prontuários. São Paulo, 2019.

\begin{tabular}{|l|l|}
\hline ESPECIALIDADE MÉDICA & $\begin{array}{l}\text { FREQUÊNCIA } \\
\text { REALIZADA (\%) }\end{array}$ \\
\hline Afecções cirúrgicas & 1,76 \\
\hline Afecções gástricas & 1,34 \\
\hline Afeções metabólicas & 0,71 \\
\hline Afecções Hematológicas & 1,15 \\
\hline Afecções Infecciosas & 1,38 \\
\hline Afecções Nefrológicas & 1,33 \\
\hline Afecções Neurológicas & 1,43 \\
\hline Afecções Ortopédicas & 2,58 \\
\hline Afecções otorrinolaringológicas & 1,43 \\
\hline Outras afecções & 1,16 \\
\hline Afecções Respiratórias & 0,96 \\
\hline
\end{tabular}

\subsection{DESCRIÇÃO DO USO DE MEDICAMENTOS CONFORME ESPECIALIDADE MÉDICA, SEGUNDO REGISTRO EM PRONTUÁRIOS}

Os dados a seguir apresentam todas as medidas farmacológicas aplicadas para as crianças com dor, segundo a especialidade clínica, seguindo a prescrição médica, conforme descrito anteriormente. Tabela 1. 
Tabela 1. Descrição do uso de medicamentos conforme especialidade médica, segundo registro em prontuários. São Paulo, 2019.

\begin{tabular}{|c|c|c|c|c|c|c|c|c|c|c|c|c|c|c|c|c|c|c|c|c|c|c|c|}
\hline \multirow{2}{*}{$\begin{array}{l}\text { Afecções } \\
\text { Medicação }\end{array}$} & & \multicolumn{3}{|c|}{1} & \multicolumn{2}{|l|}{2} & \multicolumn{2}{|l|}{3} & \multicolumn{3}{|l|}{4} & \multicolumn{2}{|c|}{6} & \multicolumn{2}{|r|}{7} & \multicolumn{3}{|c|}{8} & \multirow{2}{*}{$\begin{array}{l}9 \\
\% \\
\end{array}$} & \multicolumn{2}{|c|}{10} & \multicolumn{2}{|c|}{11} \\
\hline & & $\mathrm{N}$ & $\%$ & $\mathrm{~N}$ & $\%$ & $\mathrm{~N}$ & $\%$ & $\mathrm{~N}$ & $\%$ & $\mathrm{~N}$ & $\%$ & $\mathrm{~N}$ & $\%$ & $\mathrm{~N}$ & $\%$ & $\mathrm{~N}$ & $\%$ & $\mathrm{~N}$ & & $\mathrm{~N}$ & $\%$ & $\mathrm{~N}$ & $\%$ \\
\hline \multirow[t]{2}{*}{ Dipirona } & Não & 8 & 3,83 & 5 & 17,24 & 7 & 50,00 & 6 & 30,00 & 2 & 5,13 & 2 & 6,06 & 2 & 7,14 & 1 & 2,08 & 1 & 4,76 & 10 & 26,32 & 191 & 25,07 \\
\hline & Sim & 201 & 96,17 & 24 & 82,76 & 7 & 50,00 & 14 & 70,00 & 37 & 94,87 & 31 & 93,94 & 26 & 92,86 & 47 & 97,92 & 20 & 95,24 & 28 & 73,68 & 571 & 74,93 \\
\hline \multirow[t]{2}{*}{ Paracetamol } & Não & 179 & 85,65 & 24 & 82,76 & 12 & 85,71 & 16 & 80,00 & 28 & 71,79 & 26 & 78,79 & 21 & 75,00 & 38 & 79,17 & 17 & 80,95 & 27 & 71,05 & 641 & 84,12 \\
\hline & Sim & 30 & 14,35 & 5 & 17,24 & 2 & 14,29 & 4 & 20,00 & 11 & 28,21 & 7 & 21,21 & 7 & 25,00 & 10 & 20,83 & 4 & 19,05 & 11 & 28,95 & 121 & 15,88 \\
\hline \multirow[t]{2}{*}{ Cetoprofeno } & Não & 152 & 72,73 & 25 & 86,21 & 14 & 100,00 & 19 & 95,00 & 37 & 94,87 & 31 & 93,94 & 25 & 89,29 & 28 & 58,33 & 18 & 85,71 & 38 & 100,00 & 752 & 98,69 \\
\hline & Sim & 57 & 27,27 & 4 & 13,79 & 0 & 0,00 & 1 & 5,00 & 2 & 5,13 & 2 & 6,06 & 3 & 10,71 & 20 & 41,67 & 3 & 14,29 & 0 & 0,00 & 10 & 1,31 \\
\hline \multirow[t]{2}{*}{ Tramal } & Não & 169 & 80,86 & 28 & 96,55 & 14 & 100,00 & 20 & 100,00 & 36 & 92,31 & 32 & 96,97 & 28 & 100,00 & 26 & 54,17 & 19 & 90,48 & 38 & 100,00 & 753 & 98,82 \\
\hline & Sim & 40 & 19,14 & 1 & 3,45 & 0 & 0,00 & 0 & 0,00 & 3 & 7,69 & 1 & 3,03 & 0 & 0,00 & 22 & 45,83 & 2 & 9,52 & 0 & 0,00 & 9 & 1,18 \\
\hline \multirow[t]{2}{*}{ Ibuprofeno } & Não & 198 & 94,74 & 25 & 86,21 & 14 & 100,00 & 20 & 100,00 & 39 & 100,00 & 32 & 96,97 & 26 & 92,86 & 39 & 81,25 & 20 & 95,24 & 37 & 97,37 & 753 & 98,82 \\
\hline & Sim & 11 & 5,26 & 4 & 13,79 & 0 & 0,00 & 0 & 0,00 & 0 & 0,00 & 1 & 3,03 & 2 & 7,14 & 9 & 18,75 & 1 & 4,76 & 1 & 2,63 & 9 & 1,18 \\
\hline \multirow[t]{2}{*}{ Morfina } & Não & 204 & 97,61 & 29 & 100,00 & 13 & 92,86 & 19 & 95,00 & 39 & 100,00 & 33 & 100,00 & 28 & 100,00 & 41 & 85,42 & 21 & 100,00 & 36 & 94,74 & 760 & 99,74 \\
\hline & Sim & 5 & 2,39 & 0 & 0,00 & 1 & 7,14 & 1 & 5,00 & 0 & 0,00 & 0 & 0,00 & 0 & 0,00 & 7 & 14,58 & 0 & 0,00 & 2 & 5,26 & 2 & 0,26 \\
\hline \multirow[t]{2}{*}{ Cetorolaco } & Não & 187 & 89,47 & 29 & 100,00 & 14 & 100,00 & 18 & 90,00 & 39 & 100,00 & 33 & 100,00 & 26 & 92,86 & 41 & 85,42 & 21 & 100,00 & 37 & 97,37 & 756 & 99,21 \\
\hline & Sim & 22 & 10,53 & 0 & 0,00 & 0 & 0,00 & 2 & 10,00 & 0 & 0,00 & 0 & 0,00 & 2 & 7,14 & 7 & 14,58 & 0 & 0,00 & 1 & 2,63 & 6 & 0,79 \\
\hline \multirow[t]{2}{*}{ Xilo spray } & Não & 209 & 100,00 & 28 & 96,55 & 14 & 100,00 & 20 & 100,00 & 39 & 100,00 & 33 & 100,00 & 28 & 100,00 & 48 & 100,00 & 21 & 100,00 & 37 & 97,37 & 762 & 100,00 \\
\hline & Sim & 0 & 0,00 & 1 & 3,45 & 0 & 0,00 & 0 & 0,00 & 0 & 0,00 & 0 & 0,00 & 0 & 0,00 & 0 & 0,00 & 0 & 0,00 & 1 & 2,63 & 0 & 0,00 \\
\hline \multirow[t]{2}{*}{ Codeina } & Não & 209 & 100,00 & 29 & 100,00 & 14 & 100,00 & 19 & 95,00 & 39 & 100,00 & 33 & 100,00 & 28 & 100,00 & 47 & 97,92 & 21 & 100,00 & 38 & 100,00 & 762 & 100,00 \\
\hline & Sim & 0 & 0,00 & 0 & 0,00 & 0 & 0,00 & 1 & 5,00 & 0 & 0,00 & 0 & 0,00 & 0 & 0,00 & 1 & 2,08 & 0 & 0,00 & 0 & 0,00 & 0 & 0,00 \\
\hline \multirow[t]{2}{*}{ Simeticona } & Não & 209 & 100,00 & 29 & 100,00 & 14 & 100,00 & 20 & 100,00 & 39 & 100,00 & 33 & 100,00 & 28 & 100,00 & 48 & 100,00 & 21 & 100,00 & 38 & 100,00 & 761 & 99,87 \\
\hline & Sim & 0 & 0,00 & 0 & 0,00 & 0 & 0,00 & 0 & 0,00 & 0 & 0,00 & 0 & 0,00 & 0 & 0,00 & 0 & 0,00 & 0 & 0,00 & 0 & 0,00 & 1 & 0,13 \\
\hline \multirow[t]{2}{*}{ Buscopan } & Não & 209 & 100,00 & 29 & 100,00 & 14 & 100,00 & 20 & 100,00 & 39 & 100,00 & 32 & 96,97 & 28 & 100,00 & 48 & 100,00 & 21 & 100,00 & 38 & 100,00 & 762 & 100,00 \\
\hline & Sim & 0 & 0,00 & 0 & 0,00 & 0 & 0,00 & 0 & 0,00 & 0 & 0,00 & 1 & 3,03 & 0 & 0,00 & 0 & 0,00 & 0 & 0,00 & 0 & 0,00 & 0 & 0,00 \\
\hline \multirow[t]{2}{*}{ Xilo gel } & Não & 209 & 100,00 & 29 & 100,00 & 14 & 100,00 & 20 & 100,00 & 39 & 100,00 & 32 & 96,97 & 28 & 100,00 & 48 & 100,00 & 21 & 100,00 & 38 & 100,00 & 762 & 100,00 \\
\hline & Sim & 0 & 0,00 & 0 & 0,00 & 0 & 0,00 & 0 & 0,00 & 0 & 0,00 & 1 & 3,03 & 0 & 0,00 & 0 & 0,00 & 0 & 0,00 & 0 & 0,00 & 0 & 0,00 \\
\hline
\end{tabular}




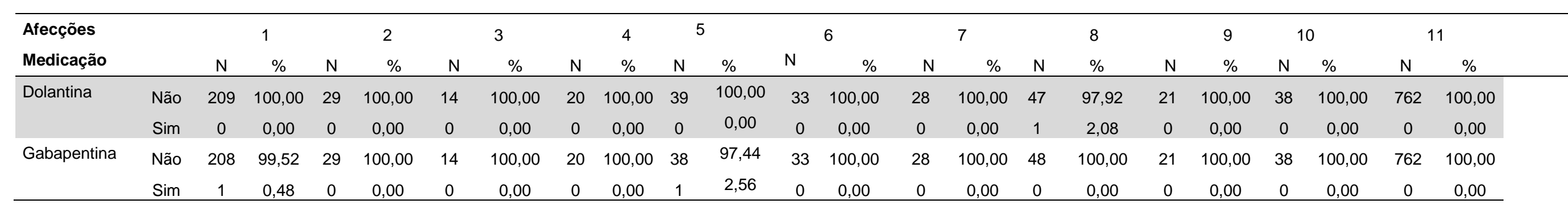

\section{Legenda}
1. Cirúrgicas
2. Gástricas
3. Metabólicas
4. Hematológicas
5. Infecciosas
6. Nefrológicas
7. Neurológicas
8. Ortopédicas
9. Otorrinolaringológicas
10. Outras
11. Respiratórias 
Quadro 3. Aplicação de medidas farmacológicas. São Paulo, 2019.

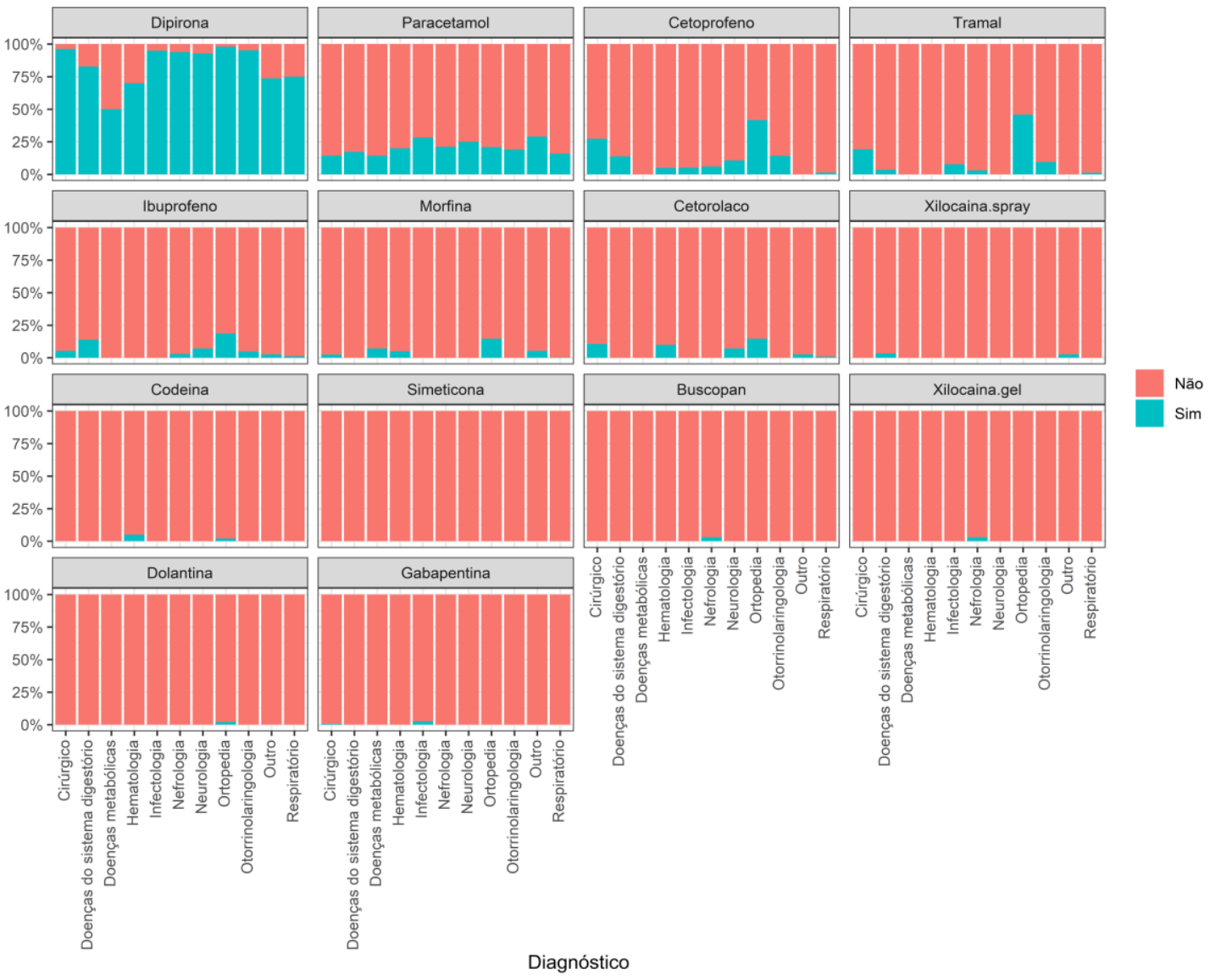

\subsection{APLICAÇÃO DE MEDIDAS NÃO FARMACOLÓGICAS}

A adoção de medidas não farmacológicas para alívio da dor em crianças internadas em um Hospital Escola do Município de São Paulo no período de coleta de dados foi de $0,4 \%(\mathrm{~N}=6)$, dentro da amostra total de 1251 prontuários, segundo informações registradas. As medidas não farmacológicas realizadas e registradas em prontuários seguem descritas no quadro abaixo, assim como diagnóstico médico, idade, escalas de avaliação de dor utilizadas e intensidade da dor (scores). 
Quadro 4. Medidas Não Farmacológicas aplicadas às crianças internadas no HU-USP, segundo registros de prontuários. São Paulo, 2019.

\begin{tabular}{|l|c|c|c|c|}
\hline \multicolumn{1}{|c|}{$\begin{array}{c}\text { Medida Não } \\
\text { Farmacológica }\end{array}$} & Diagnóstico & Idade & $\begin{array}{c}\text { Escala de } \\
\text { Avaliação }\end{array}$ & $\begin{array}{c}\text { Intensidade de } \\
\text { Dor } \\
(\text { scores })\end{array}$ \\
\hline Calor Local & Bronquiolite & 1 mês & FLACC & 3 \\
\hline $\begin{array}{l}\text { Distração (TV e } \\
\text { desenhos) }\end{array}$ & Apendicectomia & 8 anos & Numérica & $2-8$ \\
\hline Calor Local & Abscesso & 6 meses & FLACC & 6 \\
\hline Calor Local & Septicemia & 1 mês & FLACC & $2-6$ \\
\hline Distração & $\begin{array}{c}\text { Queimadura 2o } \\
\text { grau }\end{array}$ & 6 meses & FLACC & 4 \\
\hline Compressa Fria & Celulite & 7 anos & Numérica & 10 \\
\hline
\end{tabular}

\subsection{DIAGNÓSTICO DE ENFERMAGEM RELACIONADO À DOR EM PEDIATRIA}

O diagnóstico de enfermagem "dor aguda" é o diagnóstico de enfermagem mais aplicado para as crianças internadas em um Hospital Escola do Município de São Paulo, sendo o mais relacionado ao perfil das crianças atendidas.

O diagnóstico "dor aguda" foi eleito para 30,1\% ( $\mathrm{N}=375)$ das crianças internadas. Estabelecendo a relação entre a presença de dor e a eleição do diagnóstico "dor aguda", observou-se que ele foi adotado para 53,8\% ( $N=259)$ das crianças que apresentaram dor em algum momento da internação, entretanto, o diagnóstico "dor aguda" não foi eleito para 46,1\% ( $N=222)$ das crianças que tiveram dor. Curiosamente, o diagnóstico "dor aguda" também foi eleito para 14,8\% ( $N=113)$ das crianças internadas que não apresentaram dor em nenhum momento da internação, conforme quadro a seguir. 
Quadro 5. Relação entre Presença de Dor e Adoção de Diagnóstico de Enfermagem "Dor Aguda", segundo registros em prontuários. São Paulo, 2019.

\begin{tabular}{lcccc}
\hline PRESENÇA DE DOR & \multicolumn{4}{c}{ DIAGNÓSTICO DE ENFERMAGEM "DOR AGUDA" } \\
\hline \multicolumn{4}{c}{ Não } & Sim \\
& $N$ & $\%$ & N & $\%$ \\
Não & 648 & $85,15 \%$ & 113 & $14,85 \%$ \\
Sim & 222 & $46,15 \%$ & 259 & $53,85 \%$ \\
\hline
\end{tabular}

\subsection{REAVALIAÇÃO DA DOR}

A partir da amostra total da pesquisa ( $\mathrm{N}=1251$ prontuários) obteve-se $15,5 \%$ $(\mathrm{N}=194)$ de registro de reavaliações. Esse dado foi visto prioritariamente nas anotações de enfermagem, já que o impresso institucional para registro das avaliações de dor das crianças não oferece campo específico para o registro das reavaliações. 
5 DISCUSSÃO 


\section{DISCUSSÃO}

Esse estudo foi realizado com o objetivo de conhecer de que forma ocorre o manejo da dor em crianças internadas em um Hospital Escola do Município de São Paulo

Dos 1251 prontuários avaliados, a incidência de dor registrada nas crianças internadas foi de $38,7 \%$ ( $N=481)$. A média de idade das crianças internadas foi de 3,6 anos e a média do período de internação foi de cinco dias. Dentro da amostra de prontuários o registro de crianças internadas do sexo feminino foi de $42,6 \%$ ( $N=533$ ) e do sexo masculino foi de $57,3 \%(N=718)$.

O trabalho realizado por Friedrichsdorf et al. (2015) identificou que $76 \%$ das crianças ou cuidadores investigados em sua pesquisa relataram ter experienciado dor dentro de um período de 24 horas, considerando que a coleta de dados foi baseada na experiência dolorosa vivida pela criança. Bourdillon et al. (2012) relatam em seu estudo incidência de dor em $59 \%$ dos pacientes avaliados, também dentro de um período de 24 horas. Kozlowski et al. (2014) relatam em seu estudo uma incidência de dor de $86 \%$ das crianças avaliadas.

Em um trabalho realizado na Instituição local da pesquisa, foi observada uma incidência de 20,0\% ( $\mathrm{N}=14)$ de dor nas crianças internadas, entretanto, o período de coleta de dados do estudo não contemplava a trajetória da criança durante todo o período de internação e sim um momento pontual de sua permanência no hospital. Além disso, os dados foram obtidos através do relato verbal concomitante aos registros em prontuários (SALVETTI et al., 2015).

No presente estudo, os dados coletados abrangem os registros de prontuários referentes a todo o período de internação e, portanto, toda a trajetória da dor vivenciada pela criança. Isso possibilita uma visão abrangente relacionada a vários aspectos dentro da experiência de internação.

O agrupamento dos diagnósticos médicos a partir da coleta dos registros em prontuários possibilitou a identificação da frequência de dor relacionada às especialidades médicas, demonstrando, portanto, qual a especialidade médica apresentou maior incidência de dor nas crianças internadas, no período da coleta dos dados. 
As afecções de origem ortopédica e gástrica estão relacionadas à maior frequência de dor nas crianças internadas, sendo vistas em 62,5\% e 60\%, respectivamente, segundo registros em prontuários. Isso implica, teoricamente, em maior número de medidas de alívio para as crianças que se enquadram nessas categorias.

O período de internação sofreu uma variação de no mínimo três dias e no máximo 10 dias, segundo o agrupamento por especialidades médicas, considerando que os grupos que apresentaram maior número de dias de internação foram os grupos referentes a outras afecções com 10 dias de internação e o grupo de afecções metabólicas com 8,21 dias de internação. Não existe, portanto, relação direta entre o maior período de internação e maior intensidade de dor, entre as especialidades médicas.

Os resultados mostraram que a intensidade da dor foi considerada a partir da avaliação de dor com instrumentos validados, registrada em impresso institucional, no período considerado para coleta de dados. No cenário dessa pesquisa existe uma padronização para o atendimento às crianças com dor. Desde a admissão no pronto socorro infantil, a criança recebe avaliação de dor de forma sistematizada e contínua, promovendo medidas de alívio para dor.

É fundamental destacar a relevância do uso de escalas validadas para realização das avaliações de dor das crianças, o que pode ser observado no hospital de coleta de dados deste estudo. Essa conduta oferece credibilidade para que sejam tomadas as medidas mais acertadas para o alívio da dor.

Voepel-Lewis et al. (2012) destacam no trabalho realizado a importância da escolha do instrumento adequado para a avaliação de dor da criança. Salientam, ainda, a necessidade de valorizar os aspectos não verbais expostos pela criança, para uma avaliação completa e criteriosa da dor. Nesse sentido, deve-se considerar, também, a necessidade de expertise de quem avalia a criança em situação de dor.

Além disso, é fundamental considerar os aspectos emocionais da criança no momento da avaliação para que os sinais de dor não sejam confundidos com expressões de medo ou ansiedade, por exemplo (JOESTLEIN, 2015).

De acordo com os instrumentos de avaliação adotados pela instituição local da pesquisa, obteve-se maior frequência de dor nas avaliações feitas com escala de 
FACES, seguido pela avaliação com escala Numérica, escala FLACC e escala NIPS.

Isso reforça o fato do uso de instrumentos de avaliação pautada no auto relato ser considerados a melhor maneira para avaliação das crianças, inclusive, conforme descrito em uma revisão realizada por Voepel-Lewis et al. (2012).

No estudo de Linhares (2012), a prevalência de dor em crianças e adolescentes (59\%) obtida através do autorrelato, é superior aos dados obtidos através do relato de cuidadores (49\%), médicos (38\%) e enfermeiros (50\%).

No local de coleta de dados dessa pesquisa, o processo de escolha do instrumento validado a ser usado para cada criança inicia-se quando a criança é admitida na retaguarda de pronto socorro infantil.

Nesse momento, o enfermeiro recebe a criança, inicia a avaliação de dor e determina qual o instrumento validado melhor se aplica, entendendo que devem ser considerados a faixa etária de cada criança, seu desenvolvimento cognitivo e as particularidades de cada criança, como por exemplo, grau de inserção escolar e capacidade de compreensão.

Os dados obtidos neste estudo revelam que houve escolha de mais de um instrumento validado para a mesma criança. Isso pode ocorrer em casos em que a criança sofre um agravamento de seu quadro de saúde, diminuindo sua capacidade de entendimento, compreensão e responsividade diante da avaliação da dor.

Além disso, existe a possibilidade de o enfermeiro escolher a escala para avaliação da dor da criança de forma inadequada, devido à falta de conhecimento específico sobre a temática ou, dificuldade em reconhecer características específicas da criança.

Cada vez que se é proposto avaliar uma criança com dor, inicia-se um processo que engloba os aspectos sensoriais e emocionais da criança e da família. O profissional da equipe de saúde responsável por isso precisa ter conhecimento e habilidade para realizar a avaliação da dor e tende a aprimorar sua prática na avaliação da criança com dor (VOEPEL-LEWIS et al., 2012).

Entretanto existe o risco de adotar uma postura mais acomodada e deixar de explorar aspectos importantes para a tomada de conduta, que deve levar em 
consideração o julgamento baseado na compreensão dos dados coletados. Ter a avaliação implantada como quinto sinal vital, por exemplo, não garante que as avaliações explorem por completo o significado da experiência dolorosa para a criança, caso o profissional não esteja bem preparado para realizar a avaliação da dor (VOEPEL-LEWIS et al., 2012).

Um estudo realizado por Nimbalkar (2015) revela que dentre os enfermeiros avaliados, $60 \%$ apresenta conhecimento completo de questões básicas referentes ao conhecimento técnico sobre a dor na criança e, que $40 \%$ dos enfermeiros avaliados pelo estudo não tem conhecimento sobre questões básicas referentes à dor pediátrica.

Ainda nesse estudo, os enfermeiros que tem mais tempo de trabalho em áreas pediátricas possuem maior entendimento sobre as questões de dor nas crianças e, 56,12\% delas também afirmam que o conhecimento adquirido ocorreu por meio de troca de experiências com seus pares, em detrimento do conhecimento adquirido durante sua formação profissional (43\%).

Embora as instituições com programas estruturados para manejo de dor obtenham, em geral, melhor qualidade no processo de manejo da dor, ainda assim, existem estudos que mostram a falha em etapas desse processo, como por exemplo, na avaliação e nos registros sobre a dor da criança (KOZLOWSKI et al., 2014).

O estudo realizado por Habich et al. (2012), identifica melhora no processo de avaliação da dor, assim como na reavaliação, após a criação de protocolos de atendimento às crianças com dor.

Resultados de estudo mostram a necessidade de maior interação entre famílias e equipe e, que essa falha impede uma abordagem adequada às crianças $e$ consequente comprometimento no manejo da dor. (JONGUDOMKARN, D. et al., 2012).

É importante destacar que a presença de pais e cuidadores no período de hospitalização pode ser uma valiosa ferramenta na obtenção de informações a respeito da criança, em especial as crianças menores. O conhecimento sobre as reações comportamentais da criança podem facilitar e abreviar a aplicação de medidas de alívio de dor, quando necessárias. 
Olshansky et al. (2015), destacam em seu estudo a importância da comunicação efetiva para boa prática de assistência à criança com dor, considerando até mesmo problemas com idioma, abordado nesse estudo.

Considerando que a avaliação da dor na criança seja realizada de forma criteriosa e, que num dado momento seja detectado a presença de dor, espera-se que de maneira ágil e cautelosa, seja estruturado um plano de cuidados que atenda às necessidades da criança. Ou seja, aplicadas de maneira assertiva medidas farmacológicas e não farmacológicas no alívio da dor.

No presente estudo as medidas farmacológicas mais frequentemente aplicadas foram a dipirona e o paracetamol, lembrando que os registros de dor analisados consideraram prioritariamente a dor intensa como dado de pesquisa. Isso nos promove a reflexão sobre a adequação das medidas farmacológicas para alívio da dor.

O conhecimento técnico científico à respeito dos medicamentos de escolha pode interferir diretamente na promoção do bem estar da criança. Quanto maior o conhecimento muito provavelmente será mais bem aplicado medidas farmacológicas prudentes para alívio da dor.

Uma revisão integrativa realizada por Alotaibi (2018) reúne informações sobre estudos que identificam a falha do conhecimento da equipe de enfermagem nas intervenções não farmacológicas e farmacológicas, relacionadas ao uso de opioides.

A Academia Americana de Pediatria Child Life Services (2014) recomenda desde 2014, a associação entre medidas farmacológicas e não farmacológicas para que o manejo da dor ocorra de forma mais apropriada e destaca ainda que medidas não farmacológicas podem tornar-se mais efetivas que medicações.

Linhares et al. (2012) afirmam que a baixa adesão às medidas não farmacológicas pode estar associada à falta de conhecimento sobre essa modalidade de intervenção às crianças com dor, considerando que os profissionais de saúde não reconhecem essas medidas no manejo da dor.

A importância da aplicação de medidas não farmacológicas no manejo da dor recebe destaque no trabalho realizado por Lim, que relata registro de medidas não farmacológicas realizadas pelos pais das crianças. Essas medidas consideram não 
apenas a preocupação com o manejo da dor, mas também reconhecem a participação ativa dos pais no plano de ações direcionadas às crianças com dor.

A literatura produzida a respeito do manejo da dor com medidas não farmacológicas cita resultados benéficos para crianças a partir da realização de massagens, sucção não nutritiva, distração e reforço positivo, entre outros (HUI YI CHNG; YOUNG OK; KOZLOWSKI, 2015).

Neste trabalho, poucas condutas não farmacológicas foram observadas ( $\mathrm{N}=$ 6), segundo o registro em prontuários, embora na prática clínica, seja notada sua ocorrência. O impresso institucional não oferece campo específico para registro de tais condutas e isso pode favorecer falhas, pois implica na necessidade de registro em outro impresso destacando, inclusive, que os mesmos foram encontrados nas anotações de enfermagem.

Corroborando os resultados deste estudo, o trabalho realizado por Candido et al. (2015) traz resultados semelhantes no que diz respeito ao baixo índice de registros de medidas não farmacológicas em prontuários.

Considerando o período de permanência da equipe de enfermagem junto ao paciente, a aplicação de medidas não farmacológicas deve ser uma importante ferramenta dentro do plano de ações para o alívio da dor. Torna-se possível, a partir disso, a adoção dessas intervenções e posterior reavaliação, assim como, dentro dessa prática, a adoção de diagnósticos de enfermagem que visem o alívio da dor sem depender, apenas, das ações farmacológicas.

Neste trabalho, o diagnóstico de enfermagem relacionado às crianças com queixas álgicas mais frequentes foi “dor aguda". Esse diagnóstico foi eleito para 375 $(30,1 \%)$ crianças internadas que apresentaram dor em algum momento da internação.

Estabelecendo relação entre o diagnóstico de dor aguda e a presença de dor, o diagnóstico esteve presente em 259 (53,8\%) crianças. No entanto, esse mesmo diagnóstico não foi eleito para $222(46,1 \%)$ crianças que apresentaram dor. Além disso, crianças que não apresentaram quadro álgico tiveram esse diagnóstico em $113(14,8 \%)$ casos.

Vale ressaltar que, embora ainda sejam identificadas falhas no fluxo de ações para o atendimento das crianças com dor na instituição local da pesquisa, existe um 
direcionamento baseado em evidências que pode ser aprimorado e evoluir para um atendimento de excelência no tratamento à criança com dor. Esta instituição é pioneira pela implantação da sistematização da assistência de enfermagem e consequente aplicação de diagnósticos de enfermagem para o manejo da dor.

Equipes especializadas para atendimento das crianças com dor atuam de maneira mais estruturada, considerando desde a avaliação, registros e adoção de medidas não farmacológicas. Ainda assim, até em serviços onde a estruturação do atendimento à criança com dor é presente, podem ocorrer falhas no manejo da dor (KOZLOWSKI et al., 2014).

O resultado do trabalho realizado por Habich et al. (2014) também não identificou diferença na conduta de enfermeiros, no que diz respeito ao conhecimento e atitudes frente à criança com dor, mesmo depois da adoção de protocolos. Da mesma forma, Linhares et al. (2012) constataram que a equipe de saúde não reconhece protocolos e políticas para tratamento das crianças com dor, e que médicos e enfermeiros não adotam essas ações como institucionais.

Bourdillon et al. (2012) destacam em seu trabalho que a satisfação do paciente com dor aumenta quando este percebe que a equipe de saúde está realmente envolvida no processo de alívio de sua dor.

A construção de protocolos institucionais em conjunto com a equipe que presta cuidado à criança com dor favorece o entendimento das reais necessidades dessa criança e acelera a promoção do manejo adequado da dor. No entanto, pode ser visto também que a desvalorização dessas ações pode enfraquecer a prática profissional e comprometer o manejo da dor.

É possível que a lacuna existente entre a disponibilidade de protocolos e seu uso inadequado possa estar relacionada às dificuldades presentes na subjetividade da avaliação de dor em crianças; crenças profissionais a respeito da dor; sobrecarga de trabalho e falta de conhecimento técnico-científico.

Neste trabalho o registro de reavaliações de dor feitas às crianças foi constatado em 194 (15,5\%) dos 1251 prontuários analisados. Reavaliar a dor das crianças que foram submetidas a ações de alívio é fundamental para avaliar a eficácia das ações planejadas e alterar o plano de ações, caso seja necessário. 
Diante da ausência desses registros, fica implícito que ocorre uma quebra no fluxo de ações que favoreceria o alívio da dor das crianças internadas. Essa falha pode evidenciar o desconhecimento técnico da equipe e a falta de reconhecimento da sustentabilidade do processo de manejo da dor.

O Jornal da Dor publicou um estudo no qual descreve as ações de manejo da dor pautadas sobre o conceito de atenção plena. Isso implica em atender o paciente momento a momento, sem julgamentos prévios e levando em consideração aspectos físicos e emocionais. Essa abordagem influencia de maneira positiva como os pacientes enfrentam os processos dolorosos e promove maior resiliência, principalmente no caso de adolescentes (PETTER et al., 2013).

Yamada et al. (2017) destacam a importância da tomada de decisão como componente importante na prática dos profissionais envolvidos no manejo da dor e, que isso afeta enfermeiros experientes e novatos. Além disso, associam o sucesso das ações de alívio da dor a uma combinação de estratégias baseadas nas opções disponíveis para tratamento, na tomada de decisão e nas necessidades do binômio paciente-família.

Reunindo todos os dados coletados nos prontuários das crianças internadas dentro do período considerado para coleta de dados, e analisando os registros de trabalhos realizados mundialmente, relacionados com a temática desta pesquisa, pode-se traçar um paralelo com a estrutura informal das organizações citados por Kurcgant (2016), que refere fatores não explicitados, como relações interpessoais, subjetividade, valores e crenças individuais, darem significado ao trabalho que ocorre dentro das instituições.

Ainda segundo Kurcgant (2016), a estrutura de cultura e poder nas instituições não são reconhecidos devido ao componente emocional envolvido e a dificuldade em diferenciar as questões subjetivas, presente nos processos relacionais.

As questões descritas durante essa pesquisa evidenciam sua influência na avaliação da criança com dor, assim como os valores e crenças pessoais podem afetar a condução do manejo da dor nas crianças internadas. Além disso, as relações de poder implícitas entre os profissionais de saúde e as crianças e entre os vários membros de todas as equipes de saúde, permeiam a dinâmica de 
atendimento dentro da instituição, podendo influenciar na tomada de decisão mais assertiva em relação ao controle da dor.

Para que seja reconhecido e valorizado o manejo da dor na referida instituição, é importante que haja a percepção da realidade de maneira contextualizada.

"Assim, a tomada de consciência da importância de cada um nos processos de trabalho, da necessidade de participação de todos nas decisões que dizem respeito à vida na instituição, da necessidade de atualização técnicocientífica e da eficiência da responsabilidade compartilhada, bem como o entendimento dos interesses e intencionalidades do grupo em oposição, são elementos integrantes das forças de contrapoder" (KURCGANT, 2016).

Entendendo que essa citação remete todos os profissionais da equipe de saúde ao fato de adotar uma postura responsável, madura e comprometida na produção do melhor cuidado possível, diante do compromisso assumido no instante em que optam por cuidar da vida de outra pessoa. 
6 CONCLUSÃO 


\section{CONCLUSÃO}

A pesquisa realizada considerou a análise de registros de 1251 prontuários de crianças internadas num Hospital Escola do Município de São Paulo.

A partir dos dados coletados detectou-se que a frequência de dor nas crianças internadas foi de $38,7 \%(\mathrm{~N}=481)$.

A intensidade de dor apresentada pelas crianças internadas, segundo os registros em prontuários, foi considerada a partir do instrumento de avaliação validado adotado para cada criança. Portanto:

$\checkmark 41,5 \%$ das crianças avaliadas com a escala FLACC apresentaram dor intensa em algum momento da internação;

$\checkmark$ 67,7\% das crianças avaliadas com a escala Numérica apresentaram dor intensa em algum momento da internação.

$\checkmark 73,5 \%$ das crianças avaliadas com a escala de FACES apresentaram dor intensa em algum momento da internação e

$\checkmark 37,2 \%$ das crianças internadas avaliadas com a escala NIPS apresentaram dor em algum momento da internação.

Da amostra de 1251 prontuários analisados, dentre os dados obtidos:

$\checkmark 13$ crianças não receberam avaliação com nenhum tipo de instrumento validado;

$\checkmark 1172$ crianças foram avaliadas por um instrumento validado durante todo período de internação;

$\checkmark 55$ crianças foram avaliadas por dois instrumentos validados durante período de internação e

$\checkmark$ três crianças foram avaliadas com três instrumentos validados durante todo o período de internação.

A escala FLACC foi usada para avaliar $73,3 \%$ das crianças internadas; a escala numérica $21,3 \%$; a escala FACES 3,5\% e a escala NIPS 5,6\%.

$\mathrm{Na}$ instituição local de pesquisa não existe um protocolo que direcione as condutas a respeito das medidas farmacológicas e não farmacológicas, no entanto, foram observadas a adoção de ambas as medidas de alívio para as crianças com dor. 
Dentre as medidas farmacológicas mais adotadas para alívio da dor detectouse a maior frequência do uso de dipirona $(81,2 \%)$ e de paracetamol $(17,1 \%)$.

Entre as medidas não farmacológicas adotadas destacaram-se:

$\checkmark$ aplicação de calor local, constatada três vezes

$\checkmark$ distração, constatada duas vezes

$\checkmark$ aplicação de compressa fria, constatada uma vez

O diagnóstico de enfermagem é realizado de maneira sistematizada na instituição e o diagnóstico "Dor aguda" foi eleito com maior frequência, relacionado ao manejo da dor das crianças internadas, segundo registros em prontuários. $\mathrm{O}$ diagnóstico "Dor aguda" apareceu em 375 (30,1\%) dos 1251 prontuários analisados.

Quanto à ocorrência ou não da aplicação do diagnóstico "Dor Aguda":

$\checkmark$ a aplicação do diagnóstico "Dor Aguda" ocorreu para 259 (53,8\%) das crianças que apresentaram queixas álgicas em algum momento da internação;

$\checkmark$ a aplicação do diagnóstico "Dor Aguda" não ocorreu para 222 (46,15\%) das crianças que apresentaram dor em algum momento da internação.

$\checkmark$ a aplicação do diagnóstico "Dor Aguda" ocorreu para 113 (14,85\%) das crianças que não apresentaram dor em momento algum da internação.

O processo de reavaliação da dor foi observado em 194 (15,59\%) dos 1251 prontuários. 
7 CONSIDERAÇÕES FINAIS 


\section{CONSIDERAÇÕES FINAIS}

No presente estudo os dados coletados abrangeram os registros de prontuários referentes a todo o período de internação e, portanto, toda a trajetória da dor vivenciada pela criança. Isso possibilita uma visão abrangente relacionada a vários aspectos dentro da experiência de internação e disponibiliza dados inéditos referentes à instituição local de pesquisa.

A partir do conhecimento sobre o perfil dos pacientes deste estudo, surge a possibilidade de realizar junto à equipe multiprofissional uma abordagem à criança com dor, que viabilize ações para o alívio da dor de forma abrangente, mas individualizada, de acordo com cada especialidade clínica, reconhecendo as necessidades de todas as crianças com dor.

A expertise da equipe que avalia 0 paciente é fundamental para que 0 resultado da avaliação da dor permita a criação de um plano individualizado para alívio dos sintomas álgicos. O conhecimento técnico científico sobre características do desenvolvimento infantil, instrumentos de avaliação da dor, habilidades de comunicação com a criança e família promovem uma avaliação de melhor qualidade. Assim como empatia, comprometimento profissional, ausência de julgamento e desconstrução de pré-conceitos promovem melhor vínculo com a criança e, consequentemente maior entendimento sobre a presença de dor durante a internação. 


\section{LIMITAÇÕES DO ESTUDO}

A instituição de pesquisa dispõe de um impresso específico para a avaliação da dor durante todo o período de internação da criança. No entanto, nota-se a ausência de campo para registro da reavaliação de dor e adoção de medidas não farmacológicas, impedindo o total conhecimento a respeito das práticas aplicadas para o alívio da dor das crianças internadas. 
9 IMPLICAÇÕES PARA A PRÁTICA CLÍNICA 


\section{IMPLICAÇÕES PARA A PRÁTICA CLÍNICA}

Promover educação continuada acerca do manejo da dor para a equipe de saúde assim como treinamento para funcionários novos, considerando a prática baseada em evidências;

Adequar o impresso de avaliação de dor, criando campo específico para registro de reavaliação e aplicação de medidas não farmacológicas;

Elaborar um protocolo de medidas para alívio da dor, considerando a participação e contribuição da equipe multiprofissional. 
10 REFERÊNCIAS 


\section{REFERÊNCIAS}

ALOTAIBI, K., HIGGINS, I.; DAY, J.; CHAN, S. Paediatric pain management: knowledge, attitudes, barriers and facilitators among nurses - integrative review. Int Nurs Rev. 2018 Dec;65(4):524-533. doi: 10.1111/inr.12465. Jun 29, Epub 2018.

ASHISH, R.; DONGARA, SHAIL N. SHAH, SOMASHEKHAR M. NIMBALKAR, AJAY G. PHATAK, ARCHANA S. NIMBALKAR. Knowledge of and Attitudes Regarding Postoperative Pain among the Pediatric Cardiac Nursing Staff: An Indian Experience. Pain Management Nursing. Volume 16, Issue 3, p. 314-320. June, 2015.

AZIZNEJADROSHAN, P.; ALHANI, F.; MOHAMMADI, E.; Experiences of Iranian Nurses on the Facilitators of Pain Management in Children: A Qualitative Study. Pain Research and Treatment, v. 2016, n. 6, p. 1-7, 2016.

BAKER, D.W. The Joint Commission's Pain Standards: Origins and Evolution. Oakbrook Terrace, IL: The Joint Commission; 2017. Disponível em: https://www.jointcommission.org/assets/1/6/Pain_Std_History_Web_Version_051220 17.pdf. Acesso em 22 jan 2018.

BOURDILLON, F.; MONTCEL, S.T.; COLLIN, E.; COUTAUX, A.; LEBEAUPIN, E.; CESSELIN, F. BOURGEOIS, P. Deternimants os patient satisfaction regarding pain care. Revue d'Épidemiologie et de Santé Publique, v.60, p. 455-462, 2012.

BRASIL. Ministério da Saúde; Organização Mundial da Saúde. Persisting pain in children package: WHO guidelines on the pharmacological treatment of persisting pain in children with medical illnesses. Disponível em: <http://apps.who.int/iris/bitstream/10665/44540/1/9789241548120_Guidelines.pdf>. Acesso em: 22 jan. 2018.

CANDIDO, L; TACLA, M. Avaliação e caracterização da dor na criança: utilização de indicadores de qualidade. Rev enferm UERJ, jul/ago; 23(4):526-32. Rio de Janeiro, 2015.

CHILD LIFE SERVICES. Pediatrics, v. 133, n. 5, p. 1471-1478, 2014.

FRIEDRICHSDORF, S. J.; POSTIER, A.; EULL, D; WEIDNER, C.; FOSTER, L.; GILBERT, M.; CAMPBELL, F. Pain Outcomes in a US Children's Hospital: A Prospective Cross-Sectional Survey. Hospital Pediatrics, v. 5, p. 18-26, 2015.

HABICH, M.; WILSON, D.; THIELK, D; MELLES, G. L.; CRUMLETT, H. S.; MASTERTON, J.; McGUIRE, J. Evaluating the Effectiveness of Pediatric Pain Management Guidelines. Journal of Pediatric Nursing, v. 27, p. 336-345, 2012.

HERR, K.; COYNE, P.J.; McCAFFREY, M.; MANWORREN, R.; MERKEL, S. Pain assessment in the pacient unable to self-report: position statement with clinical practice recommendation. Pain Management Nursing, v.12, n.4, p.230-250, 2011.

HUI, Y. C.; HONG-GU, H.; SALLY, W. C; JOANNE, L. W. L.; LIXIA, Z.; KARIS, K. F. C. Parents' knowledge, attitudes, use of pain relief methods and satisfaction related to their children's postoperative pain management: a descriptive correlational study. Journal of Clinical Nursing, v. 24, p. 1630-1642, 2015. 
IASP - www.iasp-pain.org/Education/content. aspx?Item number $=1518$. https://s3.amazonasws.com/rdcms-

iasp/fites/production/public/content/navigationMenu/EducationResources/IASP_wait_ Times.pdf. Acesso em: 22 jan. 2018

JOESTLEIN, L. Pain, Pain, Go Away! Evidence-Based Review of Developmentally Appropriate Pain Assessment for Children in a Postoperative Setting. Orthopaedic Nursing. 34(5):252-259, September/October 2015.

JONGUDOMKARN, D.; FORGERON, P.; SIRIPUL, P; FINLEY, G. A. My child You Must Have Patient and Kren Jai: Thai Parents and Child Pain. Nursing Scholarship. v. 44, n. 4, p. 323-331, 2012.

KOZLOWSKI, L. J.; COLANTUONI, E.; THOMPSON, C. B.; VASQUENZA, K. J.; ROTHMAN, S. K.; BILLETT, C.; WHITE, E. D.; YASTER, M.; MONITTO, C. L. Pain, Prevalence, Intensity, Assessment and Management in a Hospitalized Pediatric Population. Pain Management Nursing, v. 15, n. 1, p. 22-35, 2014.

KURCGANT, P. (coord.) Gerenciamento Em Enfermagem. Rio de Janeiro: Guanabara Koogan. 3를 2016.

LAFOND, C.M.; VICENT, C.V.H.; OOSTERHOUSE, K.; WILKIE, D.J. Nurses Beliefs Regarding Pain in Crititically III Children: A Mixed-Methods Study. Journal of Pediatric Nursing, v.31, p.691-700, 2016.

LAWRENCE J, ALCOCK D, MC GRATH P, KAY J, MACMURRAY SB, DULBERG C. The development of a tool to assess neonatal pain. Neonatal Netw. 1993; 12:59-66

LINHARES, M. B. M.; DOCA, F. N. P.; MARTINEZ, A. A. P.; CASSIANO, R. G. M.; PFEIFER, L. I.; FUNAYAMA, C. A.; ROSSI, L. R. G.; FINLEY, G. A. Pediatric Pain: prevalence, assessment, and management in a teaching hospital. Brazilian Journal of Medical and Biological Research, v. 45, n. 12, p. 1287-1294, 2012.

MANOCHA, S.; TANEJA, N. Assessment of pediatric pain: a critical review: J Basic Clin Physiol Pharmacol, v. 27, p. 323-331, 2016.

MELZACK, R. The Mc Gill Pain Questionnare: major properties and scoring methods. Pain, v.1, n.3, p.277-299, 1975.

MERKEL, S L, et al. The FLACC: a behavioral scale for scoring postoperative pain in young children. Pediatr Nurs. May-Jun; 23 (3): 293-7, 1997.

OLIVEIRA, R. M.; SILVA, L. M. S.; FREITAS, C. H. A.; OLIVEIRA, S. K. P.; PEREIRA, M. M.; LEITAO, I. M. T. A. Measurement of Pain in Clinical Nursing Practice: Integrative Review. Journal of Nursing UFPE on line, v. 8, n. 8, p. 28722882, 2014.

OLSHANSKY, E.; ZENDER, R.; KAIN, Z. N.; ROSALES, A.; GUADARRAMA, J.; FORTIER, M. A. Hispanic parents' experiences of the process of caring for a child undergoing routine surgery: $A$ focus of pain and pain management. Pediatric Nursing, v. 20, p. 165-177, 2015. 
RAMIRA, M. L.; INSTONE, S.; CLARK, M. J. Pediatric Pain Management: an Evidence-Based Approach. Pediatric Nursing, v. 42, n. 1, p. 39-49, 2016.

SALVETTI, M.; BUENO, M.; ROSSATO, L.; MEDEIROS LIMA, M.; NORI, A.; GALLO FERNANDES, C.; GARCIA, P. Pain Prevalence and Associated Factors at University Hospital. The 17th World Congress on Pain is organized by the International Association for the Study of Pain. September 15, 2018.

SIEW, H. L.; MACKEY, S.; JOANNE, L. W. L; HONG-GU, H. An exploration of Singaporean parental experiences in managing school-aged children's postoperative pain: a descriptive qualitative approach. Journal of Clinical Nursing, v. 21, p. 860869, 2011.

Sociedade Brasileira para Estudo da Dor. Persisting pain in children package: WHO guidelines on the pharmacological treatment of persisting pain in children with medical illnesses. Disponível em: < http://www.sbed.org.br/materias.php?cd_secao=74\&codant=\&friurl=_-Dor-no-Brasil>. Acesso em: 22 jan. 2018.

STEVENS, B. J.; YAMADA, J.; PROMISLOW, S.; BARWICK, M.; PINARD, M. Pain Assessment and Management After a Knowledge Translation Booster Intervention. Pediatrics, v. 138, n. 4, p. 1-13, 2017.

THRANE, S.E.; WANLESS, S.; COHEN, S.M.; DANFORD, C.A. The Assessment and Non-Pharmacologic Treatment of Procedural Pain From Infancy to School Age Through a Developmental Lens: A Synthesis of Evidence With Recommendations. Journal of Pediatric Nursing, v. 31, n. 1, p.23-32, 2016.

TWIGG, O.; BYRNE, D. G.; The Influence of Contextual Variables on Judgments about Patients and Their Pain. Pain Medicine, v. 16, p. 88-98, 2014.

TWYCROSS, A.; COLLINS, S.; Nurses' Views About the Barriers and Facilitators to Effective Management of Pediatric Pain. Pain Management Nursing, v. 14, n. 4, p. 164-172, 2013.

VOEPEL-LEWIS, T.; PISCOTTY, R. J.; ANNIS, A; KALISCH, B. Empirical Review Supporting the Application of the "Pain Assessment as a Social Transaction" Model in Pediatrics. Journal of Pain and Symptom Management, v. 44, n. 3, p. 446-456, 2012.

Wong: Fundamentos de Enfermagem Pediátrica. Marilyn J. Hockenberry, David Wilson. 9ํㅡ. Ed. p. 143, 2014.

YAMADA, J.; SQUIRES, J. E.; ESTABROOKS, C. A.; VICTOR, C.; STEVENS, B. The Role of Organizational context in moderating the effect of research use on pain outcomes in hospitalized children: a cross sectional study. BMC Health Services Research, v. 17, n. 68, 2017.

ZHU, M. L.; STINSON, J.; PALOZZI, L.; WEINGARTEN, K.; HOGAN, M.; DUONG, S.; CARBAJAL, R.; CAMPBELL, F. A.; TADDIO, A. Improvements in pain outcomes in a Canadian pediatric teaching hospital following implementation of a multifaceted, 
knowledge, translation initiative. Pain Research and Management, v. 17, n. 3, p. 173-179, 2012. 
11 APÊNDICES E ANEXOS 


\section{APÊNDICE}

FORMULÁRIO DE COLETA DE DADOS

\section{CARACTERIZAÇÃO DA POPULAÇÃO}

Data coleta:

Matrícula:

Sexo: $F($ ) $M($ )

Idade:

Data nascimento: Peso:

\section{DADOS DA INTERNAÇÃO}

Diagnóstico:

Trajetória da Internação:

Analgesia Prescrita:

\section{MANEJO DA DOR NO PERÍODO DE INTERNAC̣ÃO}

Avaliação de Dor: sim ( ) não ( ) Presença de Dor: sim ( ) não ( )

Instrumento Utilizado: NIPS( ) FLACC( ) FACES ( ) NUMÉRICA ( )

Variação de Score:

Realização de Analgesia: $\quad \operatorname{sim}($ ) não ( )

Medidas não farmacológicas: sim ( ) não ( )

Reavaliação da Dor: $\quad \operatorname{sim}($ ) não ( )

Diagnóstico de "Dor Aguda": $\operatorname{sim}($ ) não ( ) 



\section{ANEXOS}

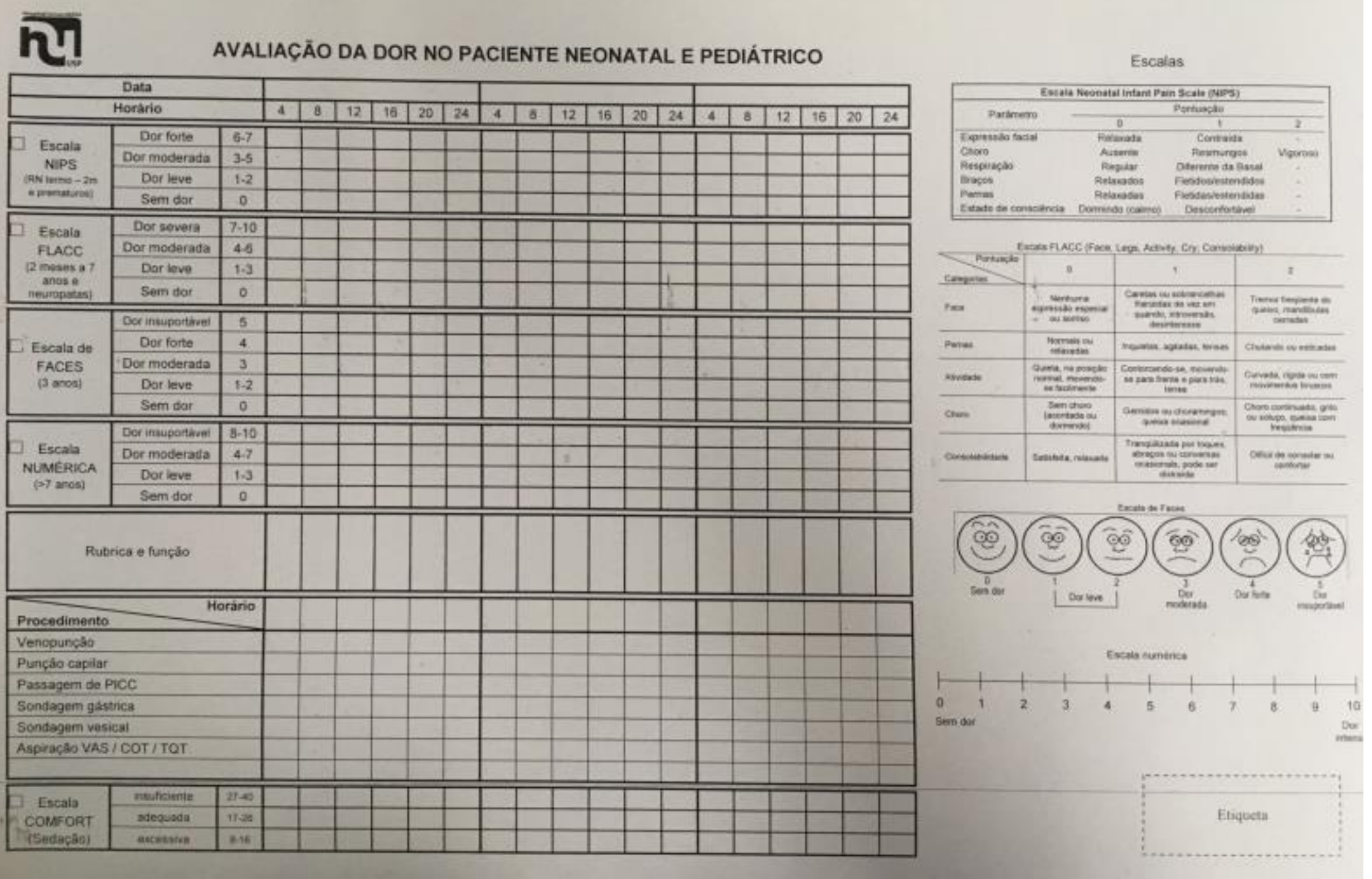




USP - ESCOLA DE
ENFERMAGEM DA
UNIVERSIDADE DE SÃO

\section{PARECER CONSUBSTANCIADO DO CEP}

\section{DADOS DO PROJETO DE PESQUISA}

Título da Pesquisa: MANEJO DA DOR PEDIÁTRICA: UM ESTUDO RETROSPECTIVO.

Pesquisador: Lisabelle Mariano Rossato

Área Temática:

Versão: 2

CAAE: 69898117.7 .0000 .5392

Instituição Proponente: Escola de Enfermagem da Universidade de São Paulo - EEUSP

Patrocinador Principal: Financiamento Próprio

\section{DADOS DO PARECER}

Número do Parecer: 2.240 .511

\section{Apresentação do Projeto:}

Trata-se de um projeto de pesquisa da Escola de Enfermagem da Universidade de São Paulo. O projeto pretende investigar as práticas de avaliação e tratamento da dor no cuidado à criança hospitalizada. $O$ estudo será retrospectivo e baseado na análise de 300 prontuários de crianças internadas na enfermaria pediátrica do Hospital Universitário da Universidade de São Paulo no período de junho de 2016 a julho de 2017. Serão incluídos os prontuários de crianças admitidas na enfermaria nesse período e cuja dor foi identificada dentro do quadro clínico no prontuário. Serão excluídos os prontuários das crianças que ficaram internadas por menos de seis horas.

Serão coletadas informações sóciodemográficas das crianças, dados da internação, diagnóstico médico e quadro clínico, anotações de enfermagem, diagnósticos e prescrições de enfermagem, prescrições médicas, avaliação e reavaliação da dor, e medidas farmacológicas e não farmacológicas utilizadas no manejo da dor Os dados serão armazenados e analisados utilizando-se o programa SPSS versão 22.0 e sofrerão análise estatística. O instrumento de coleta dos dados consta dos anexos do protocolo da pesquisa.

A proposta apresenta o cronograma de execução com término previsto para abril de 2018 . O projeto foi orçado em RS 400,00 e será custeado pela própria pesquisadora.

Endereço: Av. Dr. Eneas de Carvalho Agular, 419

Balrro: Cerquelra Cesar

CEP: $05.403-000$

UF: SP

MunicipIO: SAO PAULO

Telefone: (11)3061-8858

E-mall: cepee Qusp.br 


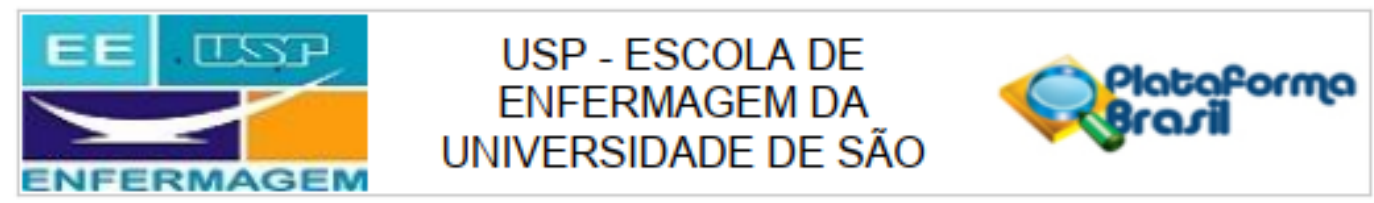

Contnuaçalo do Parecer: 2.240 .511

\section{Objetivo da Pesquisa:}

1.Identificar as práticas farmacológicas e não farmacológicas implementadas para o alivio da dor da criança nos prontuários;

2.Conhecer o perfil sócio demográfico das crianças hospitalizadas;

3.Verificar a presença do Diagnóstico de Enfermagem "Dor aguda" nos prontuários.

\section{Avaliação dos Riscos e Benefícios:}

A pesquisadora informou no formulàrio da Plataforma Brasil que o estudo "näo apresenta riscos ou danos aos pacientes, sejam biológicos, èticos ou morais, uma vez que os dados serāo obtidos por meio de busca em prontuário". Quanto aos beneficios poderá contribuir no aperfeiçoamento das práticas adotadas pelos enfermeiros com relaçäo ao alivio da dor da criança e na produçāo de conhecimento cientifico sobre o tema.

\section{Comentärios e Consideraçỏes sobre a Pesquisa:}

O projeto está estruturado de forma adequada e contempla os aspectos éticos. Consta do protocolo apresentado, a anuência da chefia da Divisão de Enfermagem Pediátrica do Hospital Universitário da Universidade de São Paulo, autorizando a realização do estudo, após a aprovação do Comitê de Ėtica em Pesquisa dessa instituiçāo.

Em atenção ao parecer anterior, o cronograma do projeto foi revisado e a fase de coleta dos dados será iniciada em 02/10/2017. A pesquisadora incluiu no formulário da Plataforma Brasil a instituição coparticipante do estudo - Hospital Universitário da Universidade de São Paulo.

\section{Considerações sobre os Termos de apresentação obrigatória:}

A pesquisadora solicitou dispensa do Termo de Consentimento Livre e Esclarecido (TCLE). Justificou que serão utilizados os dados provenientes dos prontuários das crianças e que não haverá a abordagem dos pacientes ou dos profissionais do hospital. Apresentou termo de compromisso endereçado ao Comitê de Ética em Pesquisa, responsabilizando-se pela confidencialidade e pelo sigilo dos dados obtidos na pesquisa.

\section{Recomendações:}

Näo hà recomendaçöes.

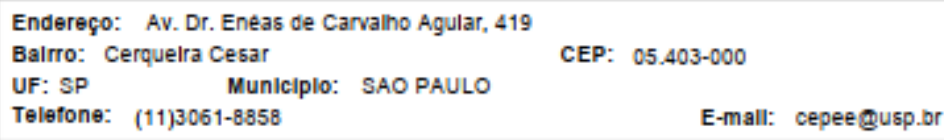




\section{EE

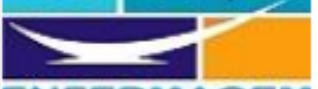 \\ ENFERMAGEM DA \\ UNIVERSIDADE DE SÃO

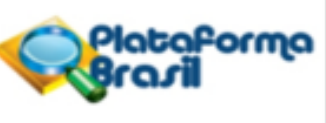

Contnusçăo do Parecer: 2.240.511

Conclusöes ou Pendëncias e Lista de Inadequaçöes:

O protocolo da pesquisa não apresenta óbices éticos que impeçam a sua realização.

Consideraçōes Finais a criterio do CEP:

- Este CEP informa a necessidade de registro dos resultados parciais e finais na Plataforma Brasil;

- Esta aprovaçāo näo substitui a autorizaçäo da instituiçäo coparticipante, antes do inicio da coleta de dados.

Este parecer foi elaborado baseado nos documentos abaixo relacionados:

\begin{tabular}{|c|c|c|c|c|}
\hline Tipo Documento & Arquivo & Postagem & Autor & Situação \\
\hline $\begin{array}{l}\text { Informações Básicas } \\
\text { do Projeto }\end{array}$ & $\begin{array}{l}\text { PB_INFORMAÇŌES_BÁSICAS_DO_P } \\
\text { ROJETO 942387.pdf }\end{array}$ & $\begin{array}{c}05 / 07 / 2017 \\
12: 06: 28\end{array}$ & & Aceito \\
\hline $\begin{array}{l}\text { Projeto Detalhado / } \\
\text { Brochura } \\
\text { Investigador }\end{array}$ & PROJETOposPENDENCIAS.docx & $\begin{array}{c}05 / 07 / 2017 \\
12: 06: 02\end{array}$ & $\begin{array}{l}\text { Lisabelle Mariano } \\
\text { Rossato }\end{array}$ & Aceito \\
\hline Cronograma & $\begin{array}{l}\text { CronogramaHUposPENDENCIASASSIN } \\
\text { ADO.pdf }\end{array}$ & $\begin{array}{c}05 / 07 / 2017 \\
12: 05: 48\end{array}$ & $\begin{array}{l}\text { Lisabelle Mariano } \\
\text { Rossato }\end{array}$ & Aceito \\
\hline Outros & TermoCompromissodoPesquisador.pdf & $\begin{array}{c}14 / 06 / 2017 \\
17: 46: 54\end{array}$ & $\begin{array}{l}\text { Lisabelle Mariano } \\
\text { Rossato }\end{array}$ & Aceito \\
\hline Outros & Instrumentoparacoletadedados.pdf & $\begin{array}{c}14 / 06 / 2017 \\
17: 38: 59\end{array}$ & $\begin{array}{l}\text { Lisabelle Mariano } \\
\text { Rossato }\end{array}$ & Aceito \\
\hline Outros & Declaracaodebeneficios.pdf & $\begin{array}{c}14 / 06 / 2017 \\
17: 36: 41 \\
\end{array}$ & $\begin{array}{l}\text { Lisabelle Mariano } \\
\text { Rossato }\end{array}$ & Aceito \\
\hline Outros & Cartadeanuenciaassinada.pdf & $\begin{array}{c}14 / 06 / 2017 \\
17: 35: 42 \\
\end{array}$ & $\begin{array}{l}\text { Lisabelle Mariano } \\
\text { Rossato }\end{array}$ & Aceito \\
\hline $\begin{array}{l}\text { Declaraçáo de } \\
\text { Pesquisadores }\end{array}$ & $\begin{array}{l}\text { DeclaracaoCompromissoPesquisador.pd } \\
\text { f }\end{array}$ & $\begin{array}{c}14 / 06 / 2017 \\
17: 16: 29 \\
\end{array}$ & $\begin{array}{l}\text { Lisabelle Mariano } \\
\text { Rossato }\end{array}$ & Aceito \\
\hline Orçamento & OrcamentoFinanceiroversao.pdf & $\begin{array}{c}14 / 06 / 2017 \\
17: 14: 16\end{array}$ & $\begin{array}{l}\text { Lisabelle Mariano } \\
\text { Rossato }\end{array}$ & Aceito \\
\hline $\begin{array}{l}\text { Declaração de } \\
\text { Instituiçấo e } \\
\text { Infraestrutura }\end{array}$ & Declaracaoinfraestrutura.pdf & $\begin{array}{c}14 / 06 / 2017 \\
17: 12: 45\end{array}$ & $\begin{array}{l}\text { Lisabelle Mariano } \\
\text { Rossato }\end{array}$ & Aceito \\
\hline Folha de Rosto & folhaderostoassinada.pdf & $\begin{array}{c}14 / 06 / 2017 \\
17: 09: 00 \\
\end{array}$ & $\begin{array}{l}\text { Lisabelle Mariano } \\
\text { Rossato }\end{array}$ & Aceito \\
\hline
\end{tabular}

Situação do Parecer:

Aprovado

Necessita Apreciação da CONEP:

Não

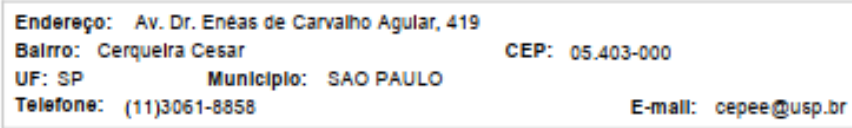




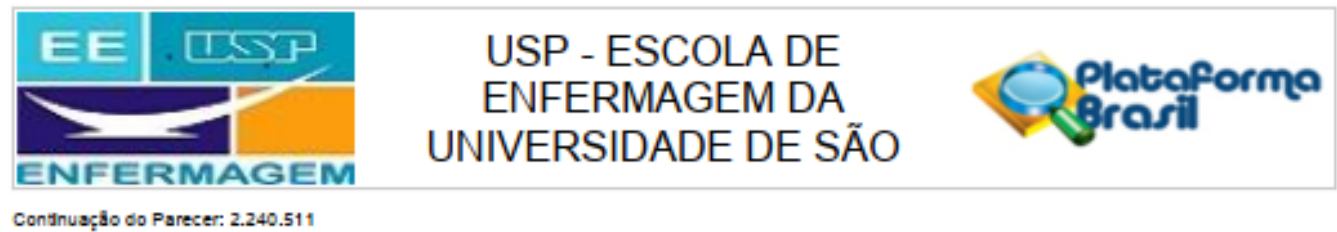

SAO PAULO, 25 de Agosto de 2017

Assinado por:

Marcelo Josè dos Santos

(Coordenador)

Endereço: Av. Dr. Eneas de Carvalho Agular, 419 